\title{
Increased ground temperatures in urban areas: Estimation of the technical geothermal potential
}

\author{
Jaime A. Rivera, ${ }^{\mathrm{a}, *}$, Philipp Blum ${ }^{\mathrm{b}}$, Peter Bayer ${ }^{\mathrm{c}}$
}

\begin{abstract}
Many cities leave a considerable thermal footprint in the subsurface. This is caused mainly by accelerated heat fluxes from warmed basements, pavements and buried infrastructures. Even though rough estimations of the theoretical heat content in urban ground exist, there is no insight available on the technical potential of such subsurface urban heat islands. By considering borehole heat exchangers (BHEs) for geothermal exploitation, new opportunities arise for planning sustainable systems within cities through utilization of accelerated ground heat input from urban structures. This is feasible at moderate heat extraction rates even without any active (seasonal) recharging of the BHEs. For typical conditions in central Europe and a given system's life time, each additional degree of urban ground heating could save around $4 \mathrm{~m}$ of the borehole length for the same heating power supply. We inspect implications for a single BHE as well as complete coverage of cities, which is approximated by an infinite field of BHEs. The results show that shallower systems favour renewable operation, and urban technical potential of geothermal use increases by up to $40 \%$ when compared to rural conditions.
\end{abstract}


27 Keywords: geothermal energy; low-enthalpy; heat transport; technical potential; subsurface urban 28 heat island 
$a$

$F_{O}$

$g$

$H$

$H^{*}$

$k$

$q$

$Q_{T}$

$r_{b}$

$R$

$R_{b}$

$t$

$t_{s}$

$t_{u r b}$

$T$

$T_{B H E}$

$T_{B W}$

$T_{F L S}$

$\Delta T_{G S T}$

$T_{k}$

$T_{I C}$ thermal diffusivity $\left(\mathrm{m}^{2} \mathrm{~s}^{-1}\right)$

Fourier number

g-function

borehole length (m)

for a given rate $q$, this is the length corresponding to the maximum $\Delta T_{G S T}(\mathrm{~m})$

geothermal gradient $\left({ }^{\circ} \mathrm{C} \mathrm{m}^{-1}\right)$

heat flow rate per unit length $\left(\mathrm{W} \mathrm{m}^{-1}\right)$

dimensionless number

borehole radius (m)

transient total thermal resistance $\left(\mathrm{m} \mathrm{K} \mathrm{W}^{-1}\right)$

effective thermal resistance of the borehole $\left(\mathrm{m} \mathrm{K} \mathrm{W}^{-1}\right)$

time (s)

characteristic time (s)

time of preexisting urban warming before BHE operation (s)

temperature in the porous medium $\left({ }^{\circ} \mathrm{C}\right)$

temperature change induced by BHE operation $\left({ }^{\circ} \mathrm{C}\right)$

temperature at the borehole wall $\left({ }^{\circ} \mathrm{C}\right)$

temperature associated with the FLS solution $\left({ }^{\circ} \mathrm{C}\right)$

net increased temperature at the ground surface $\left({ }^{\circ} \mathrm{C}\right)$

unaffected ground surface temperature $\left({ }^{\circ} \mathrm{C}\right)$

temperature associated with the IC solution $\left({ }^{\circ} \mathrm{C}\right)$ 
$x, y, z$

$x_{a}, x_{b}, y_{a}, y_{b}$

Greek symbols

$\lambda$

$\varphi$

$\tau$

$\theta$

Abbreviations

BHE

BW

FLS

GIS

GST

IC

MFLS

SIA

SUHI

TBC

TDP

VDI

Conventions

$\bar{X}$ single space coordinates where temperature is evaluated (m)

boundary coordinates of the specific land use (m)

thermal conductivity of porous medium $\left(\mathrm{W} \mathrm{m}^{-1} \mathrm{~K}^{-1}\right)$

intermediate or substitution variable

time at which a heat pulse is released (s)

dimensionless temperature

borehole heat exchanger

borehole wall

finite line source

geographical information system

ground surface temperature

initial conditions

moving finite line source

Schweizerischer Ingenieur- und Architektenverein

subsurface urban heat island

top boundary condition

temperature depth profile

Verein Deutscher Ingenieure

depth-averaged value of the quantity $X$ 


\section{Introduction}

32 The shallow ground is considered as a large energy reservoir, and the thermal capacity of low33 enthalpy geothermal installations shows global growth rates of around $7 \%$ at present [1]. Most common devices are borehole heat exchangers (BHEs), where a heat carrier fluid exchanges heat with the ambient ground by circulation in vertical boreholes. Although much more energy is stored in the ground than is used, local geothermal energy availability might be limited. Especially in areas with dense populations and high installed capacities, competition for the ground is high [2-4]. In Switzerland, for example, with the highest density of BHEs worldwide, local authorities caution overexploitation of the ground [5].

Previous works implemented GIS-based models to estimate the spatially distributed geothermal potential in specific regions or cities ([6-12]). Common to these regional models is that they consider the variability of the thermal properties of the subsurface and expected heat extraction rates, which are specified by guidelines such as the German VDI [13]. Schiel et al. [7], for instance, applied this to the city of Ludwigsburg, Germany. They compared the spatially distributed heating demands and the energy supplied by BHEs fields. In the same manner, Zhang et al. [14] estimated the spatial variability of the capacity and electricity consumption for different BHEs distributions in the city of Westminster, London. Both studies reveal how the specific heating demands may be fully or partially supplied by multiple BHEs, employing assumptions and simplifications that restrict the model.

One common simplification is related to the way these models account for urban heat sources such as heat losses from basements, underground infrastructure (e.g., tunnels, district heating and sewage networks) and heat input from increased ground surface temperature [15-19]. Generally, these influences exhibit a high variability in space and time that is commonly neglected in GIS-supported models. Depending on their strength and timing, these man-induced thermal alterations can significantly change the ground temperature down to several tens of meters in the subsurface [20]. Bayer et al. [21], for instance, employed analytical models to estimate the relative contribution of climate forcing and urban sources such as paved areas and buildings to urban ground. For this, four measured temperature-depth-profiles (TDPs) taken in areas with different degrees of urbanization in the city and suburbs of Zurich were inspected. It was demonstrated that urban structures are responsible for at least $50 \%$ of the additional energy stored in the subsurface. This is consistent with earlier work on other central European cities, which reveal large thermal anomalies in the upper urban ground, known as subsurface urban heat islands (SUHIs). These indicate accelerated heat flux from the basements of buildings and paved ground as the main drivers [22-24]. Zhu et al. [25] compared the additional energy stored in urban ground with the annual heating demand in 
several cities to calculate the geothermal potential of SUHIs. They focused on the total anthropogenic heat accumulated beneath cities (theoretical geothermal potential), However, the practically extractable energy (technical potential) of the urban subsurface is not addressed [26]. The present work intends to provide this. The objective here is the estimation of the increased technical potential of the shallow urban ground, which could be exploited by vertical ground source heat pump (GSHP) systems equipped with BHEs. As in previous GIS-based approaches, groundwater effects are neglected.

Various analytical and numerical approaches exist for simulating BHEs [27-30]. Among these, the unitary response factor approach based on $g$-functions $[31,32]$ is widely employed. In a BHE, the circulating fluid exchanges heat with the ground through conduction. The $g$-functions yield the relationship between the mean borehole wall temperature and the heat extraction rate $[33,34]$.

The $g$-functions are formulated depending on the boundary conditions at the borehole wall $[35,36]$. In the original formulation, uniform temperature was assumed, requiring an expensive and less flexible numerical solution. To improve this, analytical finite line source (FLS) models were explored [37-41]. FLS models have been proven as acceptable approximation, especially in the case of single BHEs and extended time scales $[33,42,43]$. Within the scope of this study, the FLS-based $g$-function is convenient for two main reasons. First, high-frequency signals of the heat extraction rate are not relevant here, because the focus is set on the long term performance of the BHE and the role of land-surface effects (rather than the BHE design itself). Second and more importantly, the FLS model enables the superposition of existing analytical expressions to account for increased ground surface temperatures. Consequently, this work presents a fast and analytical framework that incorporates the time-dependent interaction between the natural geothermal reservoir, urban land surface effects and technological use. Moreover, the analytical formulation facilitates direct implementation within GIS-based models as the ones described above.

In the following, we first present the modified formulation of the mean borehole wall temperature that incorporates the dynamics induced by increased ground surface temperatures (GSTs). This formulation enables the analysis of different operation schemes, including renewability criteria. The analysis is carried out for two extremes: for a single installation and for an infinite field, rendering a massive exploitation at the city scale. As a result, the technical potential of BHEs in cities with SUHIs is motivated and the methodology is demonstrated for an example case in the city of Zurich, Switzerland. 


\section{Methodology}

\subsection{Model description}

We consider the urban subsurface as a semi-infinite space with thermal conductivity $\lambda$ and thermal diffusivity $a$. In this space, BHEs are represented by line sources and the increased ground surface temperature (GST) by continuous doublets distributed over the top boundary [44, 45]. The thermal changes induced by these modeling entities, together with the initial thermal conditions, determine the temperature at any point and time. Of special interest is the temperature at the borehole wall $T_{B W}$ since it influences the heat extraction rate $q$ from the BHE [31]. This temperature can be obtained by superposing the thermal changes induced by the interacting sources. For this, the heat conduction problem should be solved for its homogeneous and non-homogenous boundary value components $[46,47]$. On the one hand, the homogeneous boundary value problem considers that the temperature at the top boundary is zero (no increased GST). Thus, the borehole wall temperature is only driven by the thermal changes induced by BHE operation, $T_{B H E}$. For these conditions, the $g$ function $g$ relates the mean borehole wall temperature $\overline{T_{B W}}$ and the heat extraction rate $q$ by [31]:

$$
\overline{T_{B W}(t)}=\overline{T_{B H E}(t)}=\frac{q}{2 \pi \lambda} \mathrm{g}\left(\frac{t}{t_{s}}, \frac{r_{b}}{H}\right)
$$

where $t$ is the time, $t_{s}=H^{2} / 9 a$ is a characteristic time, $H$ is the borehole length and $r_{b}$ is the borehole radius. In the original formulation by Eskilson [31], the $g$-function is numerically evaluated for a specific system configuration. Alternatively, by calculating the mean borehole wall temperature with the FLS model, the following semi-analytical expression is obtained $([33,38])$ :

$$
\begin{aligned}
\overline{T_{B H E}(t)}=\overline{T_{F L S}(t)} & = \\
& =\frac{q}{8 \lambda \pi} \int_{\frac{r_{b}^{2}}{4 a t}}^{\infty} \frac{1}{\varphi} \exp (-\varphi)\left\{4 \operatorname{erf}\left(\frac{H \sqrt{\varphi}}{r_{b}}\right)-2 \operatorname{erf}\left(\frac{2 H \sqrt{\varphi}}{r_{b}}\right)\right. \\
& \left.+\frac{r_{b}}{H \sqrt{\pi \varphi}}\left[4 \exp \left(-\frac{H^{2} \varphi}{r_{b}^{2}}\right)-\exp \left(-\frac{4 H^{2} \varphi}{r_{b}^{2}}\right)-3\right]\right\} d \varphi
\end{aligned}
$$

114 On the other hand, if the temperature at the ground surface is not zero, the solution of the 115 nonhomogeneous boundary value problem $T_{T B C}$ should be superposed to $T_{B H E}$, as verified by 116 Rivera et al. [44, 45] for urban land surface effects. It was also implemented by Bandos et al. [38] 117 for estimating the influence of ambient temperature in thermal response tests, and by Duan and 118 Naterer [48] for estimating the temperature beneath power transmission towers. 
119 The mean borehole wall temperature is obtained by averaging the superposed solutions over the 120 depth $H$ as follows:

$$
\overline{T_{B W}(t)}=\overline{T_{B H E}(t)}+\overline{T_{T B C}(t)}+\overline{T_{I C}}
$$

121 where $T_{I C}$ refers to the initial or undisturbed temperature. If this temperature is roughly approximated by a geothermal gradient $k$, and surface temperature $T_{k}$, the associated mean temperature along the length $H$ is $\overline{T_{I C}}=T_{k}+k H / 2$. In the original $g$-function, the temperature $T_{B H E}$ is computed for a constant background temperature [49]. In contrast, this work considers the transient effect of the increased GST (e.g. $T_{T B C}$ ) on the long term evolution of the borehole wall temperature and associated heat extraction rates. To provide the $T_{T B C}$ solution, it is necessary to consider the spatial variability of land use in cities. For this, the solution provided by Rivera et al. [44] can be formulated for selected urban areas with specified land use. These formulations are then superimposed to the global solution (application examples are shown in $[44,50,51]$ ). Here, it is assumed that each land use scenario can be characterized by its own constant or time dependent increased ground surface temperature, $\Delta T_{G S T}(t)[21,52]$. The depth-averaging of this solution over the length $H$ yields:

$$
\begin{aligned}
\overline{T_{T B C}(x, y, t)}= & \frac{1}{8 \sqrt{\pi}} \int_{\frac{H^{2}}{4 a t}}^{\infty} \Delta T_{G S T}\left(t-\frac{H^{2}}{4 a \varphi}\right)\left[\frac{1-\exp (\varphi)}{\varphi^{3 / 2}}\right]\left[\operatorname{erf}\left(\frac{y-y_{b}}{H} \sqrt{\varphi}\right)\right. \\
& \left.-\operatorname{erf}\left(\frac{y-y_{a}}{H} \sqrt{\varphi}\right)\right]\left[\operatorname{erf}\left(\frac{x-x_{b}}{H} \sqrt{\varphi}\right)-\operatorname{erf}\left(\frac{x-x_{a}}{H} \sqrt{\varphi}\right)\right] d \varphi
\end{aligned}
$$

133 where $x, y$ are the coordinates of the evaluation point in the horizontal plane and $y_{a}, y_{b}, x_{a}, x_{b}$ are 134 the coordinates of the specific land use area with temperature $\Delta T_{G S T}\left(t-H^{2} /(4 a \varphi)\right)$.

135 Initially, for the purpose of generality, it is assumed that the spatially variable GST can be represented by a mean constant value, $\Delta T_{G S T}$. For a specific location, with given land use distribution, this value could be an area-weighted GST that renders the mean annual ground surface

138 temperature. According to this, the land use effect is represented by an infinite plane that induces a 139 transient vertical heat flux into the ground. An analytical expression for this effect can be derived 140 from the solutions presented in [38, 46], which after being averaged over the reference length $H$, 141 reads: 


$$
\begin{aligned}
\overline{T_{T B C}(t)}=\frac{1}{H} \int_{0}^{H}\left[\frac{z}{2 \sqrt{\pi a}} \int_{0}^{t} \frac{\Delta T_{G S T}}{(t-\tau)^{3 / 2}} \exp \left(-\frac{z^{2}}{4 a(t-\tau)}\right) d \tau\right] d z \\
=\Delta T_{G S T}\left\{\operatorname{erf}\left(-\frac{H}{\sqrt{4 a t}}\right)+\sqrt{\frac{4 a t}{\pi H^{2}}}\left[1-\exp \left(-\frac{H^{2}}{4 a t}\right)\right]+1\right\} \\
=\Delta T_{G S T} \cdot f\left(F_{o}=\frac{a t}{H^{2}}\right)
\end{aligned}
$$

142 where $F_{o}$ is the Fourier number. To accurately superpose $\overline{T_{T B C}(t)}$ to $\overline{T_{I C}}$ in Eq. (3), $\Delta T_{G S T}$ represents 143 the excess in ground surface temperature above $T_{k}$. This means that the absolute urban ground 144 surface temperature is $T_{k}+\Delta T_{G S T}$. In Eq. (2) and Eq. (5), the time is specified by the same variable $145 t$. This means that both processes, increased GST and BHE operation, start at the same time. 146 However, a time lag between those processes may exist. In city centers for instance, the thermal forcing associated with land use changes had been acting for several decades before the installation of any BHE. If this time lag is $t_{u r b}$ and the BHE starts operation at $t=0$ then the time in Eq. (5) 149 should be $t_{u r b}+t$.

150 Taking the original $g$-function as a reference, it is necessary to obtain a dimensionless form of Eq. 151 (3) to generally describe the effect of elevated ground surface temperature. This dimensionless form 152 can be derived as follows:

$$
\begin{gathered}
{\left[\overline{T_{B W}\left(\frac{t}{t_{s}}\right)}-\overline{T_{I C}}\right] \frac{2 \pi \lambda}{q}=\overline{\theta_{B W}\left(\frac{t}{t_{s}}\right)}=\mathrm{g}\left(\frac{t}{t_{s}}, \frac{r_{b}}{H}\right)+2 \pi \frac{\lambda \Delta T_{G S T}}{q} f\left(F_{o}=\frac{t_{u r b}+t}{9 t_{s}}\right)} \\
=\mathrm{g}\left(\frac{t}{t_{s}}, \frac{r_{b}}{H}\right)+2 \pi Q_{T} f\left(\frac{t_{u r b}+t}{t_{s}}\right)
\end{gathered}
$$

153 where the dimensionless number $Q_{T}=\lambda \Delta T_{G S T} / q$, compares the strength of the surficial forcing $\Delta T_{G S T}$, to the heat extraction rate $q$, of the BHE.

According to Eq. (6), urban land surface effects increase the mean borehole wall temperature and allow a higher extraction rate $q$. By comparing these affected rates with those ones obtained under undisturbed conditions, the increased technical geothermal potential is estimated. For this, different system configurations and exploitation scenarios will be analysed.

At this point, it is worth to discuss some assumptions in the model that suggest a limited scope of applicability at first glance. One is the assumption of a homogenous porous medium. However, for 161 conduction dominated conditions, using average or effective thermal properties (homogenization), has proven to be a good approximation $[32,49]$. Another constraining assumption is the omission of 
163

164

165

166

167

168

169

170

171

172

173

174

175

176

177

178

179

180

181

182

183 184

185

186

groundwater flow in the model. On the one hand, several studies have demonstrated that thermally unaffected groundwater flow enhances the performance of GSHP systems (e.g. [53, 54]). On the other hand, significant groundwater flow close to the ground surface also promotes higher heat losses from surficial sources [55]. Preliminary analysis implementing the moving finite line source (MFLS [56]), indicates that a rather low effective thermal velocity easily overprints any ground surface temperature effects on the mean borehole wall temperature. In these cases, (thermally) undisturbed groundwater flow shapes the thermal plumes without changing significantly the overall energy balance $[57,58]$. A few studies have been carried out in urban areas significantly influenced by dynamic aquifers where the presented analytical models have limited applicability. These studies necessarily rely on measurements and numerical simulations of the interaction of these aquifers and near-surface urban sources [59-62].

\subsection{Scenarios of analysis}

There are diverse standards for BHE installation and planning in different countries [63] that typically restrict induced ground temperature variations, heat extraction rates and/or the lifetime of the geothermal system. This work considers the regulations for planning and construction provided by the Swiss Society of Engineers and Architects (SIA). Specifically, its norm 384/6 defines the lowest allowed temperature in the circulating fluid of ground coupled heat pumps. According to the norm, the mean fluid temperature should not be lower than $-1.5^{\circ} \mathrm{C}$ after 50 years of operation [64]. If this mean fluid temperature is $\overline{T_{\text {fluid }}}$, then it is possible to relate this temperature and Eq. (3) as follows [32]:

$$
\overline{T_{\text {fluid }}}=\overline{T_{T B C}\left(t_{u r b}+t\right)}+\overline{T_{I C}}+q R(t)=\overline{T_{B W}(t)}+q R_{b}
$$

where the sum $\overline{T_{T B C}\left(t_{u r b}+t\right)}+\overline{T_{I C}}$ is usually referred to as the undisturbed ground temperature, $R(t)$ is the transient total thermal resistance and $R_{b}$ is the effective thermal resistance of the borehole. For an unbalanced extraction rate $q, \overline{T_{B H E}(t)}+q R_{b}$ acts against the background temperature provided by $\overline{T_{T B C}\left(t_{u r b}+t\right)}+\overline{T_{I C}}$.

Two scenarios are discussed in the following:

- The "depleting scenario", which corresponds to a finite operation period of 50 years.

- The "renewable scenario", which corresponds to an infinite operation period, where the heat extraction rate is balanced by natural sources $[3,65]$. 
191 Results for both scenarios are discussed along with their corresponding 'base case', which refers to 192 the undisturbed conditions. In this way, the net energy gain is associated with urban effects, and 193 thus the related technical potential can be quantified and discussed.

194 The analyses are carried out for a reference site, specified by the parameters listed in Table 1 . The 195 given values of the geothermal gradient, the thermal diffusivity and the thermal conductivity are 196 representative for the city of Zurich [21] and are characteristic for unconsolidated sediments 197 typically found beneath many central European cities [66]. The magnitude of $R_{b}$ is within the 198 expected range of values for long term BHE operation [49]. Finally, the value for $T_{k}$ is site specific 199 and corresponds to the estimations for the city of Zurich described in [21].

Table 1: Parameters for the reference site taken from $[21,66]$.

\begin{tabular}{|l|c|}
\hline Parameter & Value \\
\hline Thermal diffusivity, $a\left(\mathrm{~m}^{2} \mathrm{~s}^{-1}\right)$ & $1 \times 10^{-6}$ \\
\hline Thermal conductivity, $\lambda\left(\mathrm{W} \mathrm{m}^{-1} \mathrm{~K}^{-1}\right)$ & 2.5 \\
\hline Borehole radius, $r_{b}(\mathrm{~m})$ & 0.1 \\
\hline Effective borehole thermal resistance, $R_{b}\left(\mathrm{~W}^{-1} \mathrm{~m} \mathrm{~K}\right)$ & 0.15 \\
\hline Background surface temperature, $T_{k}\left({ }^{\circ} \mathrm{C}\right)$ & 10 \\
\hline Vertical geothermal gradient, $k\left({ }^{\circ} \mathrm{C} \mathrm{m}^{-1}\right)$ & 0.03 \\
\hline
\end{tabular}

202 For the following analysis, a range of borehole lengths $(H)$ between $50 \mathrm{~m}$ and $200 \mathrm{~m}$ is considered. 203 The upper limit is chosen based on observed urban temperature-depth-profiles (TDPs) that typically 204 show thermal anomalies reaching up to $150 \mathrm{~m}$ depth [17, 20]. Moreover, the upper limit of $200 \mathrm{~m}$ 205 minimizes the effect of inaccuracies in the analytical model related to the assumption of an uniform 206 heat extraction rate along the depth [67]. This assumption may be critical for deeper applications 207 because with higher ground temperatures (due to the geothermal gradient) it is expected that heat 208 extraction rates also increase with depth. Finally, for specification of increased urban ground209 surface temperature, $\Delta T_{G S T}$, a range of $0.5-5 \mathrm{~K}$ is chosen according to the findings in [22, 23]. 


\section{Results and discussion}

\subsection{Single BHE}

\subsubsection{Effect of land surface forcing on mean borehole wall temperature}

214 The dimensionless mean borehole wall temperature $\left(\overline{\theta_{B W}}\right)$ is crucial for estimating the technical 215 geothermal potential, and it is scrutinized first. Figure 1a shows the influence of increasing ground216 surface warming (expressed by $Q_{T}$ ), assuming that urban ground heating and BHE operation start 217 simultaneously $\left(t_{u r b}=0\right)$. The curve $Q_{T}=0$ corresponds to the original $g$-function without the 218 transient effect induced by $\Delta T_{G S T}$. In this case, the sustained drop in $\overline{\theta_{B W}}$ is due to the continuous 219 heat extraction $q$. For $\Delta T_{G S T}>0$, the quantity $Q_{T}=\lambda \Delta T_{G S T} / q$ increases proportionally to its magnitude. The associated curves depicted in Figure 1a exhibit a characteristic minimum in $\overline{\theta_{B W}}$. The time at which this minimum occurs indicates the instant when GST effects balance the temperature drop induced by $q$ such that the heat flux from the surface compensates the heat extraction. At later times, continuously high ground-heat flux replenishes the cooled ground. Pronounced $\Delta T_{G S T}$ is associated with a higher mean borehole wall temperature.
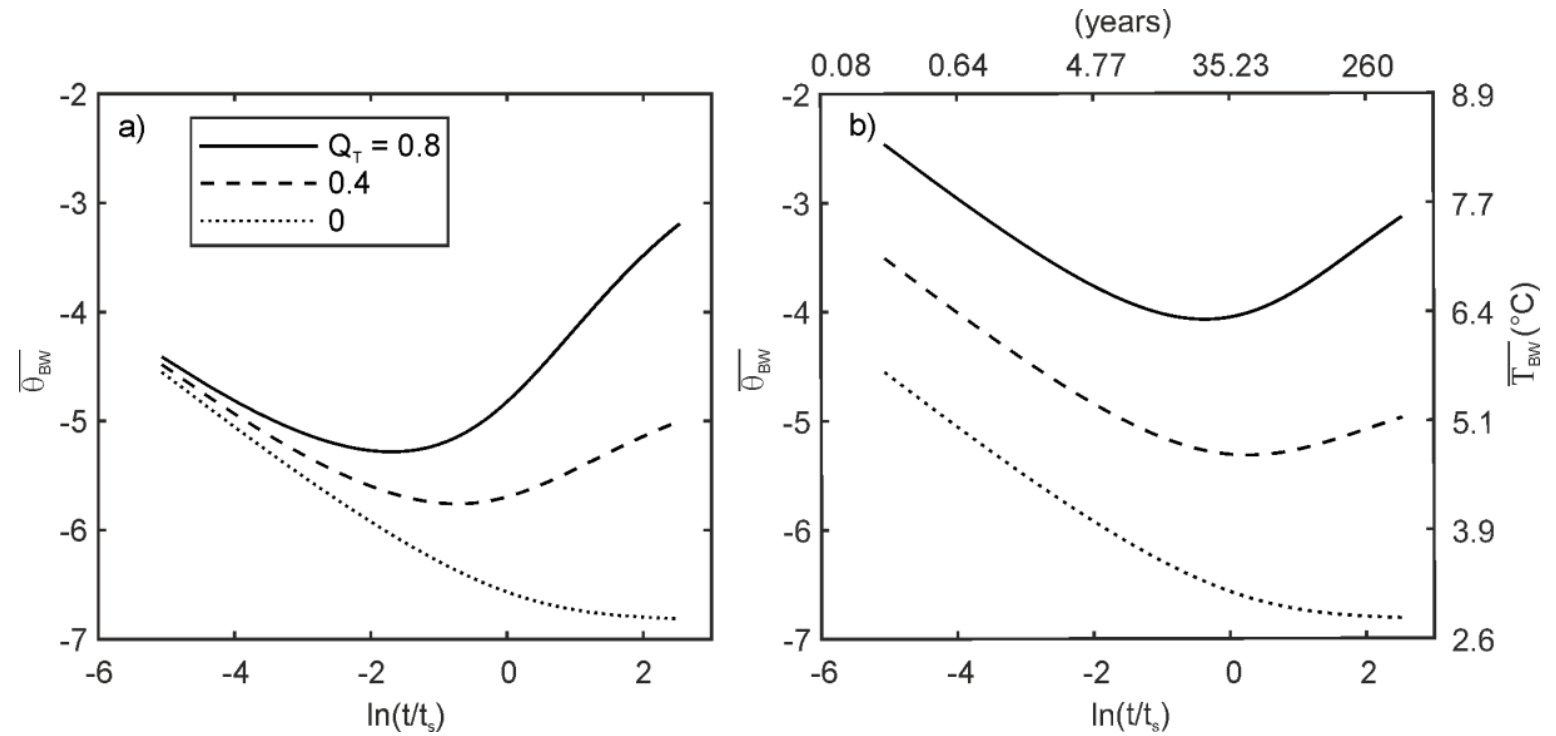

Figure 1: Dimensionless mean borehole wall temperature over dimensionless time: a) $t_{u r b}=0$ years and b) $t_{\text {urb }}=100$ years (the magnitudes in ${ }^{\circ} \mathrm{C}$ and years correspond to the parameters shown in Table 1 with $q=20 \mathrm{~W} \mathrm{~m}^{-1}$ and $H=100 \mathrm{~m}$ ). A higher $Q_{T}$ indicates a stronger effect from $\Delta T_{G S T}$ relative to the heat extraction rate $q . Q_{T}=0$ is the original g-function neglecting urbanization effects.

Figure $1 \mathrm{~b}$ examines the same conditions as in Figure 1a, but assumes that urbanization has started 100 years ago $\left(t_{u r b}=100\right.$ years). In this case, a subsurface urban heat island (SUHI) pre-exists before the BHE operation. The influence of increased ground-surface temperatures as expressed by 
$235 Q_{T}$ is clearly enhanced, especially at early operation times. This is a consequence of the linear 236 superposition of the different solutions indicated in Eq. (3). For a given borehole length $H$, there is a 237 time when SUHI covers this depth and the changes in the mean borehole wall temperature start to 238 diminish. If the operation time of the BHE is several times longer than this characteristic time, then 239 at the end of the time window, $\overline{\theta_{B W}}$ becomes insensitive to $t_{u r b}$ (Figure 1b).

240 The described temporal dynamics of the mean borehole wall temperature can be transferred to the

241 mean fluid temperature $\overline{T_{\text {fluid }}}$ via Eq. (7). In this way, it is possible to estimate the heat extraction 242 rates that fulfil the conditions of the depleting and renewable scenarios as discussed in the 243 following.

\section{$244 \quad 3.1 .2$ Depleting scenario}

245 The depleting scenario assumes that the reservoir is exhausted after 50 years of operation. For this 246 condition, Figure 2 depicts the technical geothermal potential for different timings and intensities of 247 surface warming.

248 Figure 2a shows the heat extraction rates for $t_{u r b}=0$ and 100 years. These rates are mean annual 249 values and are of the same magnitude as those discussed in [7, 49, 68]. While these rates have 250 values between $26-27 \mathrm{~W} \mathrm{~m}^{-1}$ for the lowest assumed ground surface warming $\left(\Delta T_{G S T}=0.5 \mathrm{~K}\right)$, they 251 reach values higher than $30 \mathrm{~W} \mathrm{~m}^{-1}$ at the upper limit of $\Delta T_{G S T}=5 \mathrm{~K}$. Clearly, the rates are more 252 sensitive to $\Delta T_{G S T}$ for the shallower BHEs.

253 The characteristic curvature is the result of the complementary effect between the initial thermal 254 conditions given by the geothermal gradient and the increased GST on top. For a given iso-rate 255 curve $q$, there is a length $H^{*}$ above and below which the extraction rate $q$ can be kept at lower $256 \Delta T_{G S T}$. For a BHE with $H>H^{*}$, the natural geothermal gradient dominates and thus, the rate $q$ is 257 sustained by decreasing $\Delta T_{G S T}$. 

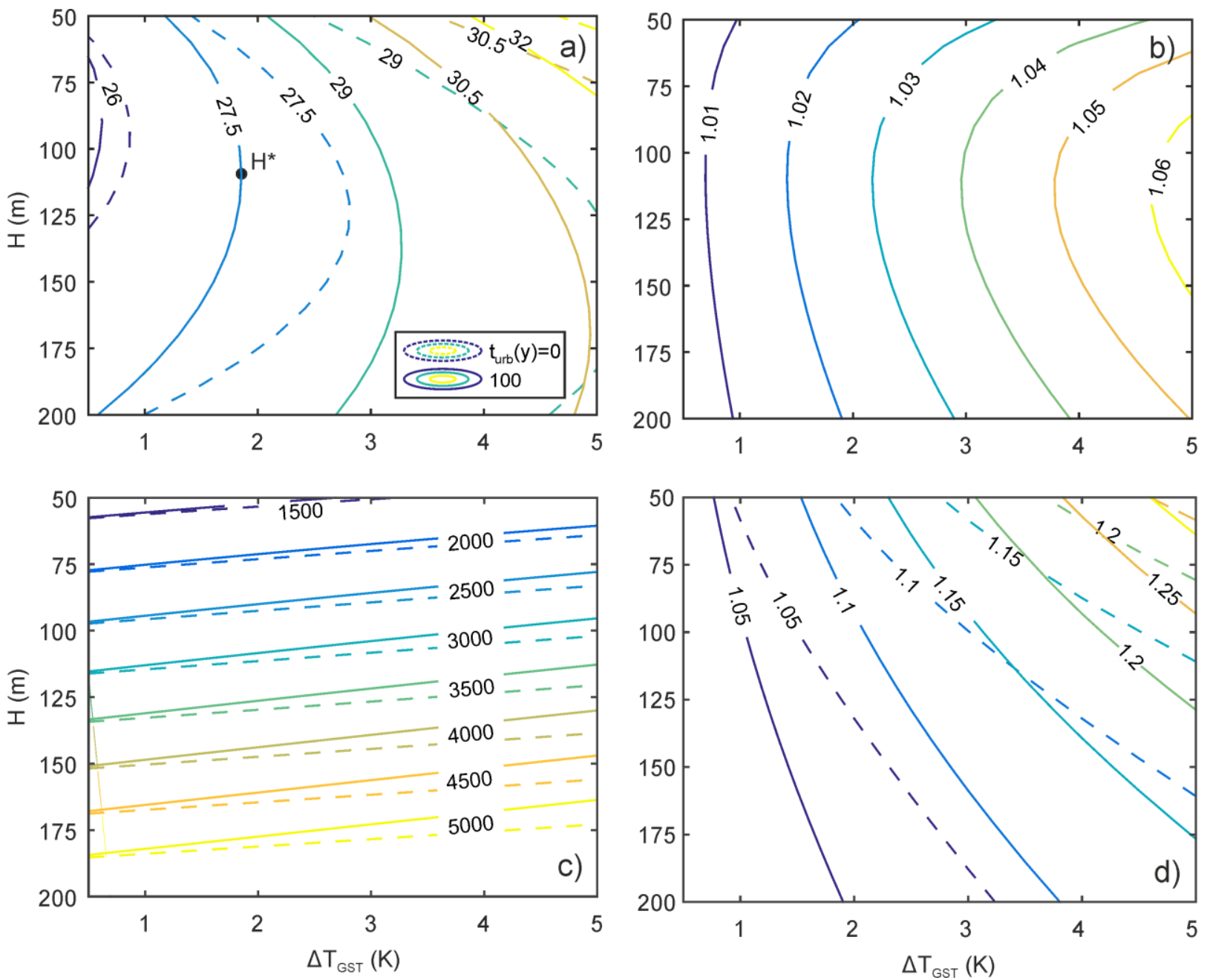

Figure 2: Single BHE in the depleting scenario: a) heat extraction rates $\left.q\left(\mathrm{~W} \mathrm{~m}^{-1}\right), \mathrm{b}\right)$ ratio $q\left(t_{u r b}=100\right) / q\left(t_{u r b}=0\right)$ for the rates shown in a), c) extracted power $(\mathrm{W})$, and d) ratio between the rates shown in a) and the ones from the base case (excluding the urban effect). Exemplarily, $H^{*}$ is the length that requires the maximum $\Delta T_{G S T}$ keeping $q=27.5 \mathrm{~W} \mathrm{~m}^{-1}$.

For any selected point in the domain of Figure $2 \mathrm{a}$, the extraction rates are higher for $t_{u r b}=100$ years than for $t_{u r b}=0$ years. For better insight, the ratio of the rates $q\left(t_{u r b}=100\right.$ years $) / q\left(t_{u r b}=0\right.$ years) is depicted in Figure 2b. It is shown that the gain in $q$ due to 100 years of urbanization ranges between $1 \%$ and $6 \%$. The minimum $\Delta T_{G S T}$ for a given curve is an indicator for the penetration depth of $\Delta T_{G S T}$ in the 100 years period. Taking for example $\Delta T_{G S T}=3 \mathrm{~K}$, the maximum relative gain from this preexisting GST is obtained for a BHE with borehole length of $H \approx 112 \mathrm{~m}$.

Figure 2c indicates the total power extracted from a single BHE. The power is mainly controlled by $H$. However, for a given power, elevated ground surface temperature tends to decrease the required BHE length at an approximate rate of $4.5 \mathrm{~m}$ for $1 \mathrm{~K}$. For a $2 \mathrm{~kW}$ demand (annually averaged) and assuming $\Delta T_{G S T}=0.5 \mathrm{~K}$, for instance, a BHE has to be drilled $80 \mathrm{~m}$. This is reduced to $60 \mathrm{~m}$ given a value of $\Delta T_{G S T}=5 \mathrm{~K}$. Note that in practice, planning of appropriate BHE configuration also has to consider high frequencies in the energy demand (daily and hourly loads), which may appreciably 
increase the required length [69]. These results imply that an optimized use of the stored energy in urban areas can be achieved by combining more shallow BHEs to supply the base demand and fewer deep exchangers for buffering peak loads. An analogous strategy combining exchangers with different lengths is shown in [67] for very deep BHEs $(H>600 \mathrm{~m})$.

280 Figure $2 \mathrm{~d}$ shows the gain on total power (or heat extraction rates) by considering urban ground surface effects relative to the undisturbed base case $\left(\Delta T_{G S T}=0\right)$. This is the increased technical geothermal potential associated with urban ground warming. For very low $\Delta T_{G S T}$, this gain is less than $5 \%$ while it could reach up to $30 \%$ depending on the time lag $t_{u r b}$ and the strength of $\Delta T_{G S T}$. As expected, the shallower the BHE is, the higher the relative gain in power. For a BHE with $200 \mathrm{~m}$ length, this gain for the studied depleting scenario ranges between $5 \%$ and $13 \%$, even after 100 years of urban ground heating.

Menberg et al., Benz et al. and Zhu et al. [22, 61, 70] have studied the subsurface urban heat island phenomenon in several German cities. Zhu et al. [61] for instance, specifies for the city of Cologne magnitudes of $\Delta T_{G S T}$ ranging between $2-4 \mathrm{~K}$ in build-up areas and more than $5 \mathrm{~K}$ in the city center. Taking into account that downtown cities are generally the oldest areas, the increased geothermal potential of a single BHE with $H=100 \mathrm{~m}$ could be between $10 \%$ and $25 \%$ higher than in less affected rural environments (Figure 2d). Besides, its inherent spatial variability, $\Delta T_{G S T}$ changes significantly with time. It is also influenced by multi-scale climate conditions, evolution in land use, surficial characteristics of pavements, and insulation of basements. The increased geothermal potential shown in Figure $2 d$ therefore represents an averaged first-order estimation. Application to a specific site with temporally and spatially variable conditions is demonstrated later in Chapter 3.3.

The ratios depicted in Figure $2 \mathrm{~d}$ depend on the initial thermal conditions, minimum allowed fluid temperature and thermal diffusivity. Considering for instance a representative $\Delta T_{G S T}=4 \mathrm{~K}$ and $H=$ $100 \mathrm{~m}$, the ratio is around 1.20. If the thermal diffusivity is between $50 \%$ and $200 \%$ of the reference value (Table 1), this ratio could vary between 1.21 and 1.26 for a low $T_{k}=8{ }^{\circ} \mathrm{C}$ or between 1.16 and 1.21 for a high $T_{k}=12{ }^{\circ} \mathrm{C}$. This means that within the feasible ranges for diffusivities and non-affected GST in central European cities [70], the ratios in Figure 2d are still robust estimates.

\subsubsection{Renewable scenario}

305 Given the conditions of the previous depleting -scenario, the reservoir will be exhausted after 50 306 years of operation. Of similar interest are the conditions under which an unlimited exploitation in 307 time can be achieved. The analysis is motivated by the response of $\overline{T_{B W}}$ to ground surface temperature effects characterized in Figure 1. Taking for example the curve with $Q_{T}=0$, which 
corresponds to the original $g$-function that ignores urbanization, it is shown that a 'renewable operation' is feasible approximately for $\ln \left(t / t_{s}\right)>2$. At these times, axial effects and heat input

311 from the ground surface compensate the continuous drop in the mean borehole wall temperature as 312 discussed in [57]. However, reaching this state would require an operation time longer than 260 313 years for the parameters of Table 1 with $H=100 \mathrm{~m}$.

314 As can be seen also in Figure 1, for $Q_{T}>0$, i.e. when accounting for urbanization, a sustainable 315 operation can be achieved from the time when $\overline{\theta_{B W}}$ gets minimal. This minimum is reached earlier 316 depending on the strength of $\Delta T_{G S T}$ relative to $q$ (measured through the dimensionless number $Q_{T}$ ). 317 Figure 3 a depicts how this minimum changes as a function of $t_{u r b}$ and $Q_{T}$. With the lowest $Q_{T} \approx 0$, 318 the minimum is reached at $\ln \left(t / t_{s}\right)>2$ as discussed earlier. However, taking a realistic $\Delta T_{G S T}=4$ $319 \mathrm{~K}$ and $q=20 \mathrm{~W} \mathrm{~m}^{-1}$, we obtain $Q_{T}=0.5$. Then, for $H=100 \mathrm{~m}$, the minimum is reached after 32 320 years for $t_{u r b}=100$ years $\left(\ln \left(t / t_{s}\right) \approx-0.1\right)$ or even after 12 years if $t_{u r b}=0$ years $\left(\ln \left(t / t_{s}\right) \approx-\right.$ 321 1.1). The larger $t_{u r b}$ is, the longer $\Delta T_{G S T}$ has been acting before the BHE. Thus, it takes longer for the line source to balance the positive thermal effect of $\Delta T_{G S T}$ (see also Figure $1 \mathrm{~b}$ ). However, when reaching the minimum $\overline{\theta_{B W}}$ faster, this means lower mean borehole temperatures.
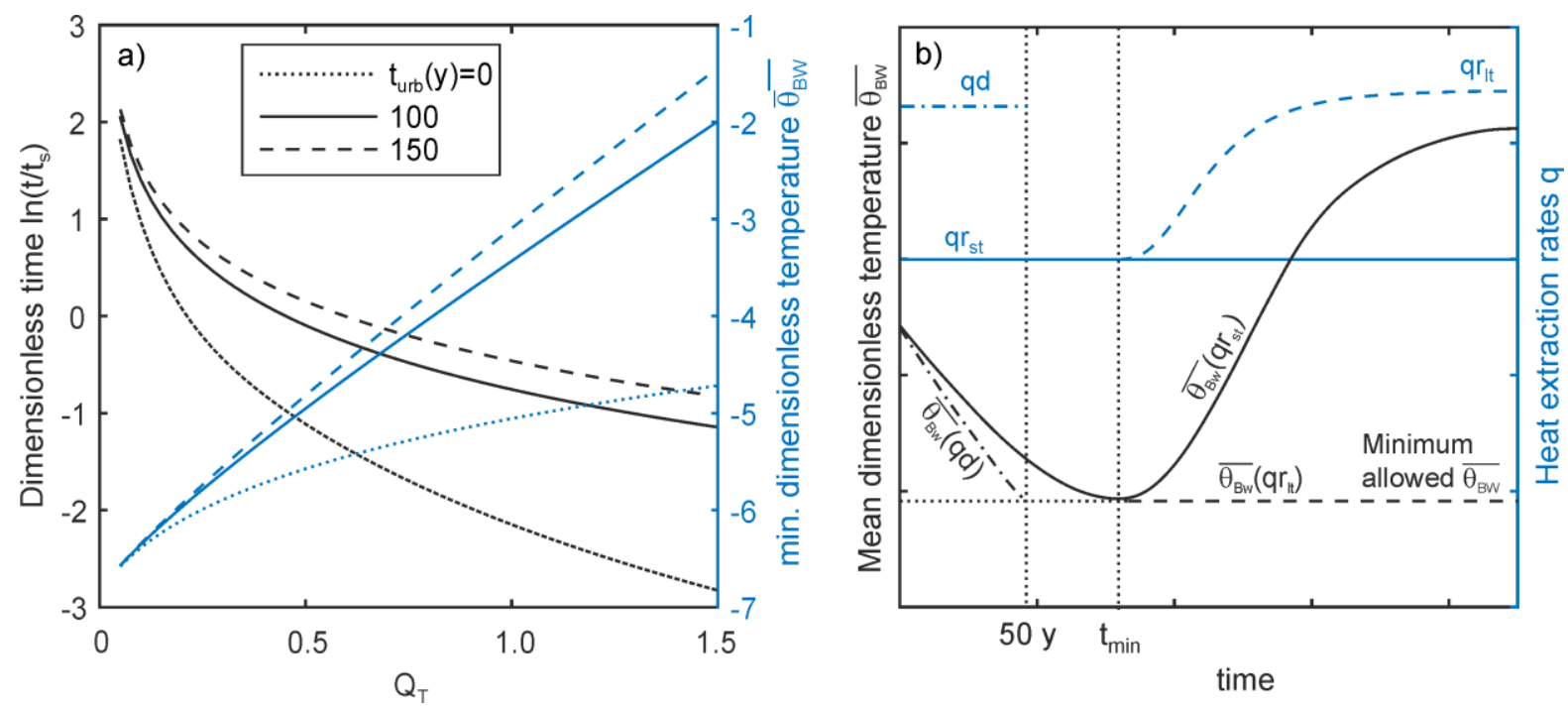

Figure 3: a) Minimum dimensionless borehole temperature, $\min \left(\overline{\theta_{B W}}\right)$, and associated dimensionless time $\ln \left(t / t_{s}\right)$, referential absolute magnitudes for time (years) and $\overline{T_{B W}}\left({ }^{\circ} \mathrm{C}\right.$ ) can be seen in Figure $1 \mathrm{~b}$; b) schematic $\left(\overline{\theta_{B W}}\right)$ (left axis) and corresponding heat extraction rates $q$ (right axis) for the depleting $(q d)$ and renewable $(q r)$ scenarios. Rates $q r$ are distinguished for the short term $\left(q r_{s t}\right)$ and for the long term $\left(q r_{l t}\right) . Q_{T}=\lambda \Delta T_{G S T} / q$ and $t_{u r b}$ is the time lag (in years) between the start of BHE operation and the pre-existing $\Delta T_{G S T}$ effect.

During simulation, the minimum temperature $\overline{T_{\text {fluid }}}$ can be set to the SIA's temperature threshold, and the corresponding maximum possible extraction rates can be computed (Eq. (7)). In the 
334 following, these rates are called "renewable rates". The ratios of these rates relative to the 335 renewable ones obtained from the base case $\left(\Delta T_{G S T}=0 \mathrm{~K}\right)$ are shown in Figure 4a. These ratios are 336 very similar to the ones shown in Figure $2 \mathrm{~d}$ (depleting operation), especially for $t_{u r b}=100$ years 337 with values between 1.05 and 1.30. Figure 4a however suggests a lower sensitivity to $H$ that can be 338 inferred from the depicted gradient, particularly for longer BHEs. This means that for obtaining a 339 similar ratio as in Figure $2 \mathrm{~d}$, a lower $\Delta T_{G S T}$ is needed under renewable conditions. Still, the absolute 340 renewable heat extraction rates are generally lower compared to the depleting scenario. This is 341 summarized in Table 2.

342 After reaching the minimum $\overline{T_{B W}}$, the effect of $\Delta T_{G S T}$ is more relevant than the rate $q$, and the 343 borehole wall temperature increases (Figure 1). Theoretically, it would be possible to further 344 increase the heat extraction rates (for example by increasing the heating demand associated to the 345 specific geothermal system) so that $\overline{T_{B W}}$ is kept at the given temperature threshold from that time 346 on. The resulting heat extraction rate would be constant in time until the minimum temperature 347 threshold is reached and then the rate could be increased monotonically until it arrives at a 348 maximum value (Figure $3 \mathrm{~b}$ ). At this maximum, the transient effect of $\Delta T_{G S T}$ disappears, a new 349 thermal equilibrium in the ground is reached and $\overline{\theta_{B W}}$ becomes again identical to the original $g$ 350 function with $Q_{T}=0$. The initial thermal conditions however are now defined by the geothermal 351 gradient and a new equilibrated ground surface temperature, which is the superposition of $\Delta T_{G S T}$ 352 and $T_{k}$.
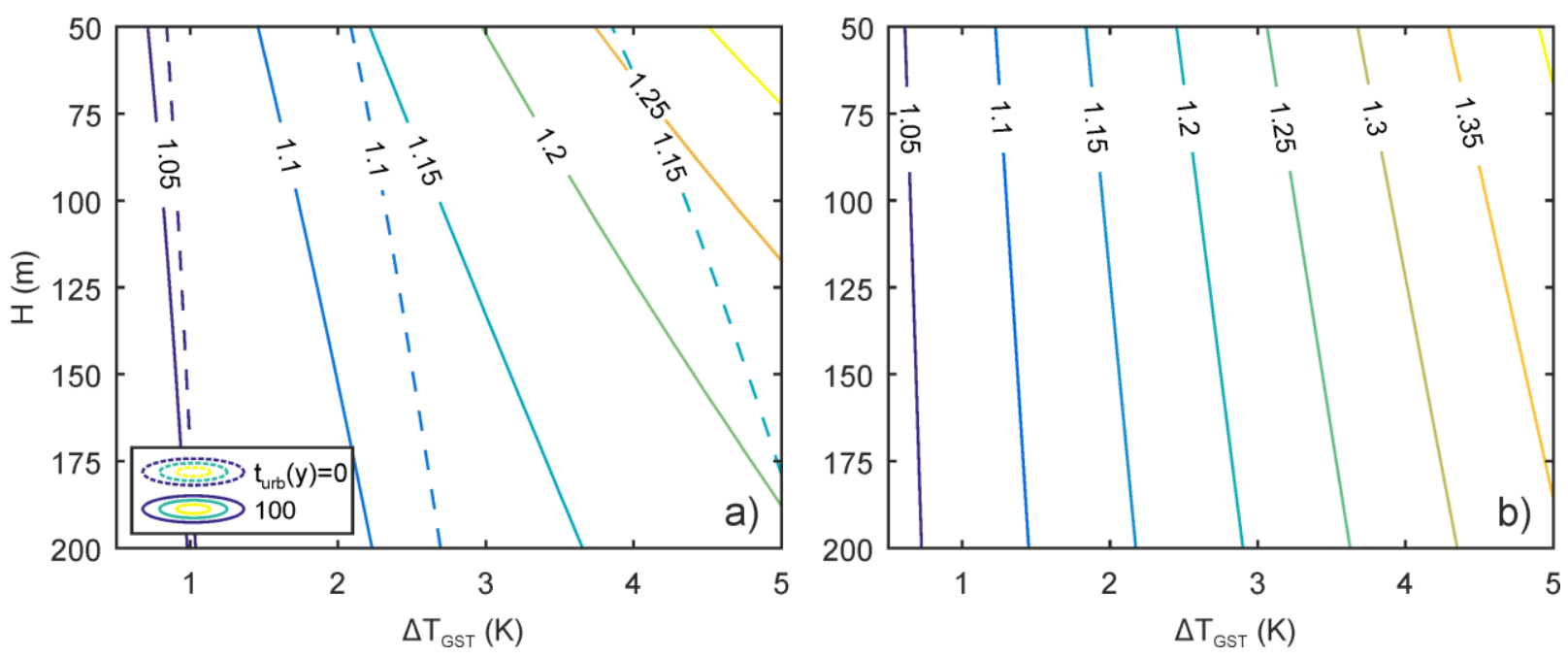

Figure 4: Ratio between the renewable heat extraction rates with and without urban effects at: a) short-term or minimum and b) long-term or asymptote in the mean borehole wall temperature.

Figure $4 \mathrm{~b}$ presents the ratios between the long-term maximum rates and the base case. By comparing Figure $2 \mathrm{~d}$ and Figure $4 \mathrm{~b}$, it is shown that in the long-term renewable rates are between 5 
$\%$ and $10 \%$ higher than those calculated in the depleting scenario with prescribed life time of 50 years.

\subsection{Infinite BHE field}

Previous analysis reveals the consequence of urban ground heating for single BHE performance, but on the city scale, the concerted use of multiple BHEs has to be accounted for [7, 9, 71]. In such configurations or fields, the interaction and competition among BHEs may reduce the extractable heat per BHE when compared with a single installation [72]. For estimating the full urban technical geothermal potential, we therefore consider an extreme case, which is an infinite BHE field with borehole spacing $B$ (squared lattice) and length $H$. This field mimics the idealistic behaviour of a non-optimized large scale exploitation in a city, where all BHEs are similarly operated. These conditions facilitate the simulation through superimposed line sources, which invoke the linearity of the heat transport equation with known or constrained heat extraction rates at the borehole wall [33, $37,73]$. Following analysis continues using the parameters of the reference site listed in Table 1.

\subsubsection{Depleting scenario}

In the first step, the depleting scenario again considers mean fluid temperatures above $-1.5{ }^{\circ} \mathrm{C}$ during 50 years of operation. Figure 5 depicts the energy densities in $\mathrm{kWh}$ per square meter and per year as a function of borehole length or installation depth $H$, and spacing $B$. The effect of long-term urbanization prior to BHE installation is included by assuming $t_{u r b}=100$ years. Figure 5a represents conditions of low ground heating of $\Delta T_{G S T}=1 \mathrm{~K}$, which could be found for example beneath green spaces [22]. In comparison, a stronger ground heating of $\Delta T_{G S T}=5 \mathrm{~K}$ is depicted in Figure 5b. As expected, in both figures, the highest energy densities are obtained for the deepest and more packed configurations.

For a separation of $30 \mathrm{~m}$ between standalone installations, for instance, Figure $5 \mathrm{~b}$ gives energy densities between 13 and $33 \mathrm{kWh} \mathrm{m}^{-2} \mathrm{a}^{-1}$ depending on the field depth. Taking the referential heating energy demands specified in Schiel et al. [7] for city buildings (between 102.3 and 207.1 $\mathrm{kWh} \mathrm{m}^{-2} \mathrm{a}^{-1}$ ), this would imply that for $H=200 \mathrm{~m}$, the shallow ground could supply between $32 \%$ $(33 / 102.3)$ and $16 \%(33 / 207.1)$ of these energy requirements for 50 years. 

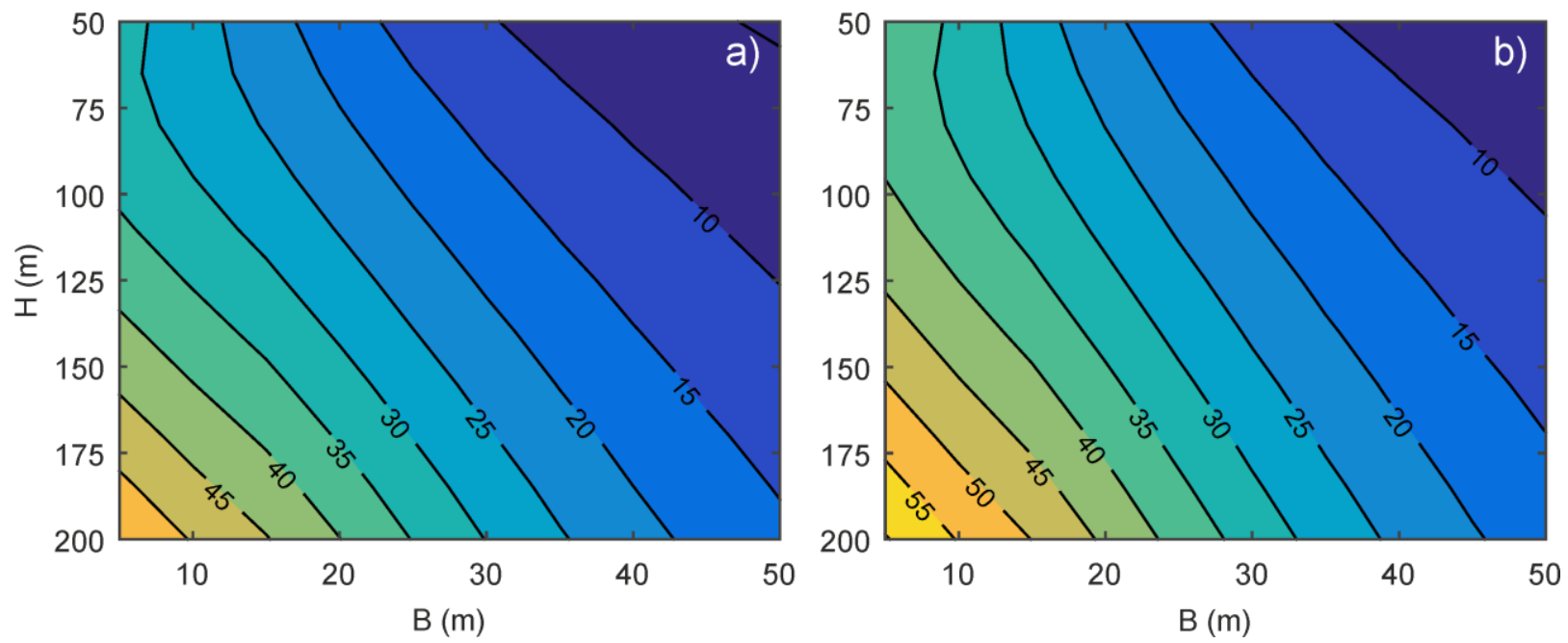

Figure 5: Energy densities $\left(\mathrm{kWh} \mathrm{m}^{-2} \mathrm{a}^{-1}\right)$ for the infinite field with $t_{\text {urb }}=100$ years under the depleting scenario: a) $\Delta T_{G S T}=1 \mathrm{~K}$ and b) $\Delta T_{G S T}=5 \mathrm{~K}$

In this depleting scenario where the calculation time is fixed $\left(t=t_{u r b}+50\right.$ years), the ratio between energy densities, affected and unaffected (base case) by $\Delta T_{G S T}$, is independent of the separation $B$. Thus, the estimated increased technical geothermal potential computed for single BHE installations (Figure 2b, d) is also valid for the infinite field.

\subsubsection{Renewable scenario}

Renewable use refers to heat extraction that does not only guarantee regulatory limits (here minimum of $-1.5^{\circ} \mathrm{C}$ for heat carrier fluid) for a given time (here 50 years), but also beyond. As shown for single BHE operation (Chapter 3.1.3), continued reservoir depletion is associated with advancing replenishment, and ultimately ground heat flux can stimulate thermal recovery.

400 For a BHE in a field, the corresponding mean borehole wall temperature $\overline{\theta_{B W}}$ behaves similarly to 401 the one shown in Figure 1a for a single BHE and $Q_{T}=0$, but with lower magnitudes due to the interference with neighboring BHEs. The time for reaching renewable operation conditions in the 403 base case (i.e., the curve's plateau) is also higher since influences from distant BHEs extend the 404 transient behavior.

405 The effect of including an increased ground surface temperature is shown in Figure 6. The energy 406 densities are lower and clearly different from those in Figure 5 (depleting scenario). In the latter, the 407 highest energy density is obtained with a deeper field, while in the renewable scenario, the 408 shallowest field is favored. This is due to the unconstrained exploitation time under renewable 409 conditions. To fulfil this, the system is forced to take more heat from increased GST rather than 
411 for the most packed fields.
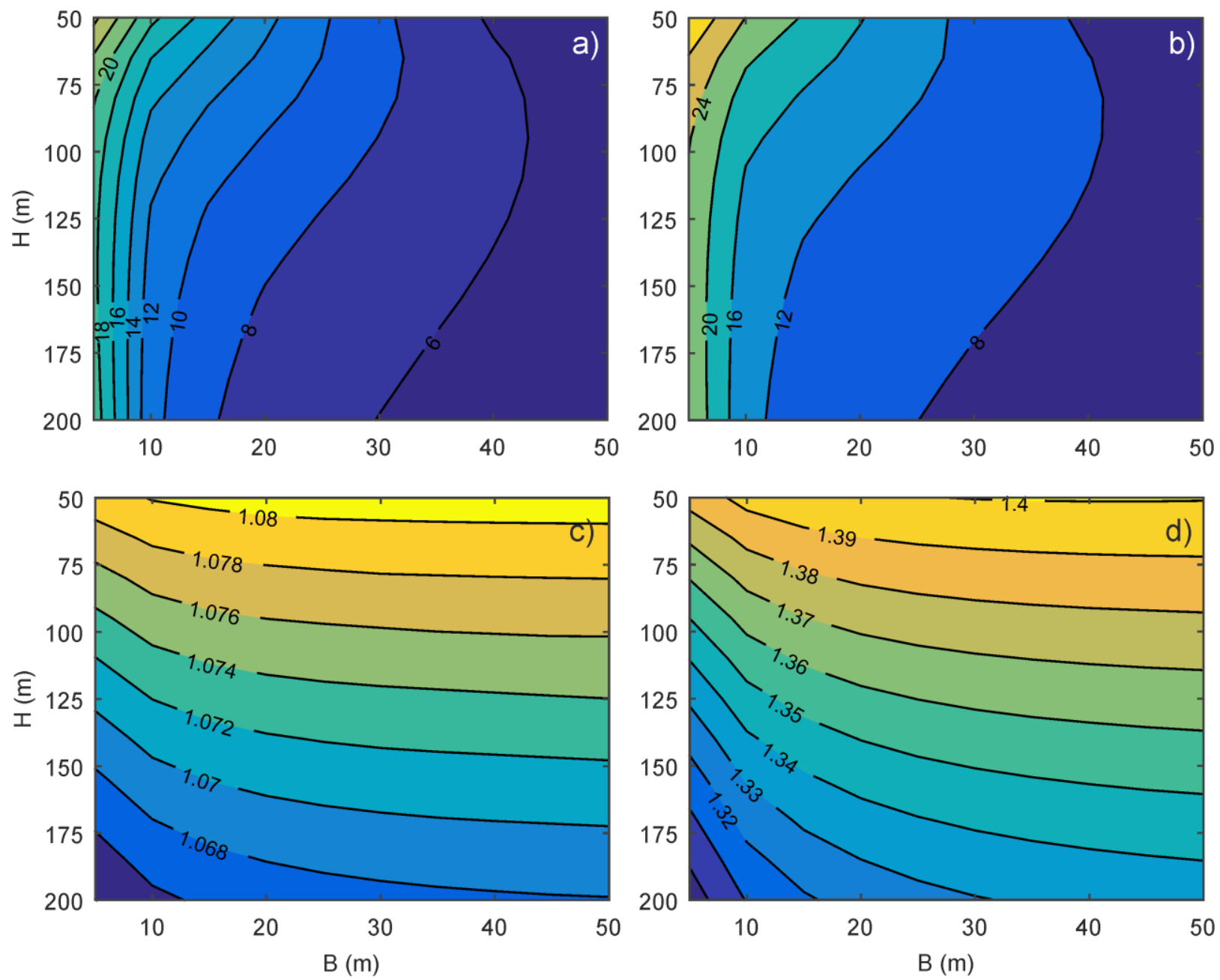

Figure 6: Energy densities $\left(\mathrm{kWh} \mathrm{m}^{-2} \mathrm{a}^{-1}\right)$ : a) $\Delta T_{G S T}=1 \mathrm{~K}$, b) $\Delta T_{G S T}=5 \mathrm{~K}$, c) ratio of renewable rates with $\Delta T_{G S T}=1 \mathrm{~K}$ with respect to the renewable base case and d) ratio of renewable rates with $\Delta T_{G S T}=5 \mathrm{~K}$ with respect to the renewable base case.

Figure 6a depicts the case of $\Delta T_{G S T}=1 \mathrm{~K}$ with minor heat flux. The ratio between these densities and those from the base case $\left(\Delta T_{G S T}=0 \mathrm{~K}\right)$ is depicted in Figure 6c, and urbanization here yields up to $8 \%$ higher densities, and consequently, extraction rates. An increased ground surface temperature of $1 \mathrm{~K}$ might be associated with a loose and open development in suburban areas.

421 Taking again the energy heating demands specified in [7] for this type of settlement $\left(57.7 \mathrm{kWh} \mathrm{m}^{-2}\right.$ $422 \mathrm{a}^{-1}$ ), the results indicate that it would be possible to supply between $14 \%-17 \%$ of this demand in a 423 renewable way. To accomplish this, BHEs of around $100 \mathrm{~m}$ long are required with a separation 424 between $20-30 \mathrm{~m}$.

425 Figure $6 \mathrm{~b}$ depicts the other extreme: renewable energy densities for $\Delta T_{G S T}=5 \mathrm{~K}$, such as is 426 common in many city centers. By relating to the densities in the base case, Figure $6 \mathrm{~d}$ indicates that 
427 the renewable rates in the city center would be between around $30 \%-40 \%$ higher than outside the 428 city.

429 From the comparison with the depleting densities shown in Figure 5b, it can be concluded that the 430 latter are between $25 \%-65 \%$ higher. The value of $25 \%$ refers to the most shallow and packed 431 fields, and $65 \%$ to the deepest and more spread fields. A related analysis is presented in Table 2 in 432 terms of absolute heat extraction rates $\left(\mathrm{W} \mathrm{m}^{-1}\right)$ for both exploitation scenarios and different system 433 configurations. In general, for single BHEs the SIA's requirements seem to be a good guideline to 434 ensure renewability since discrepancies to the depleting scenario are not significant. For the infinite 435 field however, the situation is different especially for longer systems. Under non-urbanized 436 conditions ('Base case' in Table 2) for example, depleting rates could be about six times higher than 437 the renewable ones $(H=200 \mathrm{~m}$ and $B=20 \mathrm{~m})$. This difference declines with shallower systems and 438 stronger urban effect $\left(\Delta T_{G S T}\right)$ reaching values between 1.19 and 1.40 for $H=50 \mathrm{~m}$ and $\Delta T_{G S T}=5 \mathrm{~K}$.

Table 2: Heat extraction rates $\left(\mathrm{W} \mathrm{m}^{-1}\right)$ for a single $(B=\infty)$ and a representative BHE in an infinite field for different degrees of urbanization and exploitation schemes, and $t_{u r b}=100$ years. R: renewable scenario, D: depleting scenario.

\begin{tabular}{|c|c|c|c|c|c|c|c|c|c|}
\hline \multirow[b]{3}{*}{ H (m) } & \multirow[b]{3}{*}{ B (m) } & \multirow{2}{*}{\multicolumn{2}{|c|}{$\begin{array}{c}\text { Base case } \\
\Delta T_{G S T}=\mathbf{0} \mathbf{K}\end{array}$}} & \multirow{2}{*}{\multicolumn{2}{|c|}{$\begin{array}{c}\text { Low development } \\
\Delta T_{G S T}=\mathbf{1 ~ K} \\
\end{array}$}} & \multirow{2}{*}{\multicolumn{2}{|c|}{$\begin{array}{c}\text { Suburban } \\
\Delta T_{G S T}=\mathbf{3} \mathbf{K}\end{array}$}} & \multirow{2}{*}{\multicolumn{2}{|c|}{$\begin{array}{c}\text { Urban } \\
\Delta T_{G S T}=\mathbf{5} \mathbf{K}\end{array}$}} \\
\hline & & & & & & & & & \\
\hline & & $\mathbf{R}$ & D & $\mathbf{R}$ & D & $\mathbf{R}$ & D & $\mathbf{R}$ & D \\
\hline \multirow{4}{*}{50} & 10 & 3.9 & 5.8 & 4.2 & 6.2 & 4.8 & 6.9 & 5.5 & 7.7 \\
\hline & 20 & 10.6 & 14.7 & 11.4 & 15.6 & 13.1 & 17.6 & 14.8 & 19.4 \\
\hline & 30 & 16.0 & 20.0 & 17.3 & 21.3 & 19.8 & 23.9 & 22.4 & 26.5 \\
\hline & $\infty$ & 25.4 & 25.5 & 27.2 & 27.2 & 30.5 & 30.5 & 33.9 & 33.9 \\
\hline \multirow{4}{*}{100} & 10 & 1.4 & 3.3 & 1.5 & 3.5 & 1.7 & 3.8 & 1.9 & 4.1 \\
\hline & 20 & 4.1 & 10.1 & 4.4 & 10.6 & 5.0 & 11.6 & 5.6 & 12.6 \\
\hline & 30 & 7.5 & 15.9 & 8.1 & 16.7 & 9.2 & 18.2 & 10.3 & 19.8 \\
\hline & $\infty$ & 24.7 & 25.3 & 26.2 & 26.5 & 28.8 & 28.9 & 31.3 & 31.3 \\
\hline \multirow{4}{*}{200} & 10 & 0.6 & 2.8 & 0.6 & 2.8 & 0.7 & 3.0 & 0.7 & 3.1 \\
\hline & 20 & 1.5 & 8.9 & 1.6 & 9.2 & 1.8 & 9.6 & 2.0 & 10.1 \\
\hline & 30 & 2.9 & 14.9 & 3.1 & 15.3 & 3.4 & 16.1 & 3.8 & 16.9 \\
\hline & $\infty$ & 25.4 & 27.1 & 26.7 & 27.8 & 28.7 & 29.2 & 30.4 & 30.6 \\
\hline
\end{tabular}

443 Finally, it is interesting to compare the energy densities of Figure $6 \mathrm{~b}$ with the corresponding heating 444 energy demand in urban settlements (between 102.3 and $207.1 \mathrm{kWh} \mathrm{m}^{-2} \mathrm{a}^{-1}$ ) [7]. For the most 445 optimistic scenario $(B<10 \mathrm{~m}, H<60 \mathrm{~m}$ ), it would be possible to supply $13-27 \%$ (in a renewable 446 way) of the heating demand associated with settlements, such as downtown city buildings. For more 447 realistic BHE separation of $B=20-30 \mathrm{~m}$, this percentage would be only between $6 \%$ and $16 \%$. 448 These numbers of course are restricted to the parameters of the presented case study (Table 1). 


\subsection{Case study}

This case study aims at demonstrating the applicability of the methodology at a real site with specific (time dependent) land use distribution. It does not only include the effect of elevated heat flux from urban structures, but also atmospheric warming due to long-term climate change. The site is located in the suburb of Meilen in the city of Zurich (Figure 7a), where a temperature-depth profile (TDP) was measured prior to BHE operation (Bayer et al. [21]). For this site, Figure 7b shows the most influential urban structures that can be classified as buildings (B) or pavements (A). Most of the buildings were built within the period between 1959-1972. However, three on the west side (B17-B19) date back to 1884. The streets are also rather old with an age of more than 100 years.
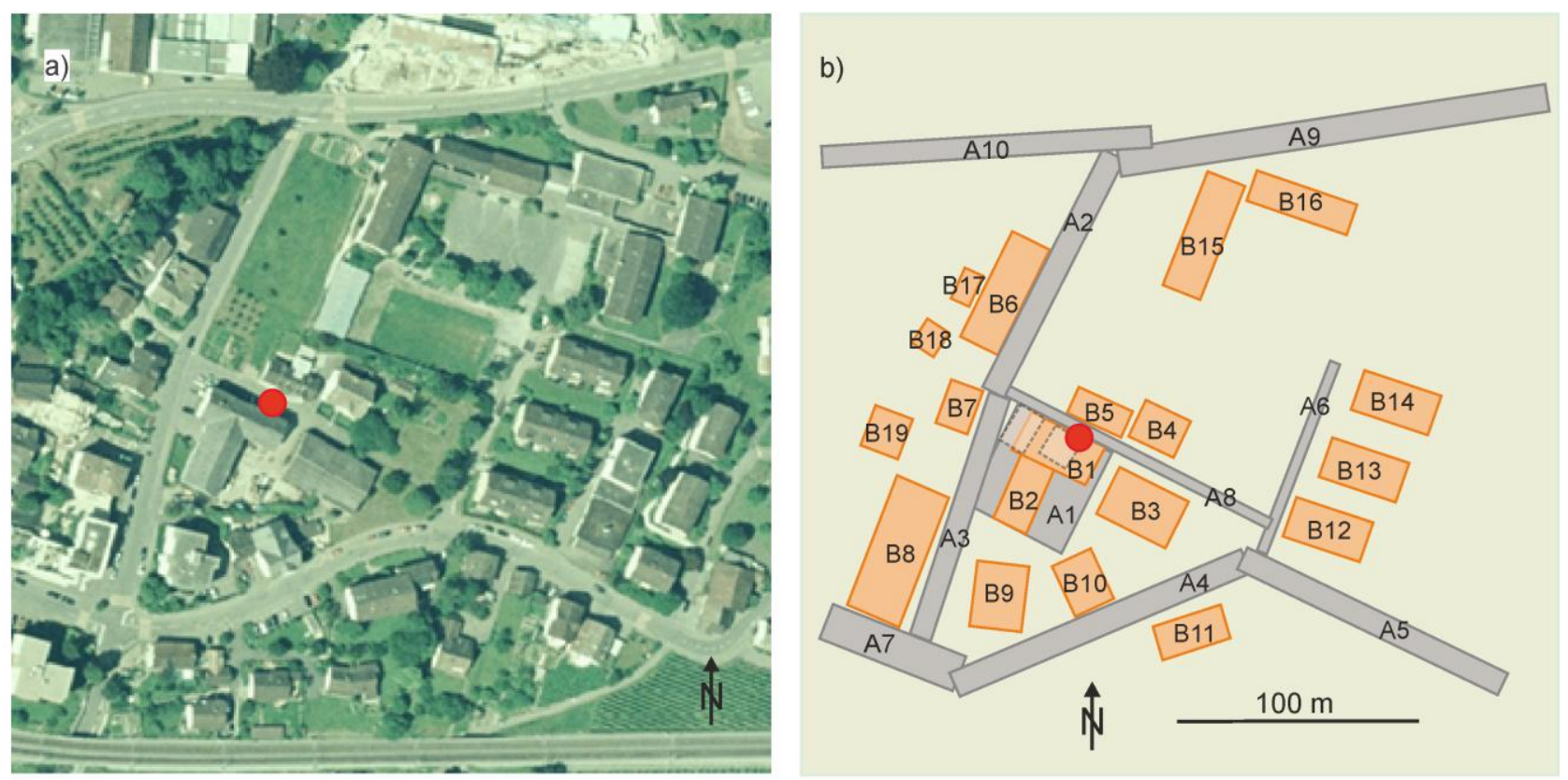

Figure 7: a) Plan view of the site as of 2005 [74] and b) influencing buildings (B) and pavements (A). The lighter orange areas surrounded by dashed lines represent buildings demolished in 1959, whose thermal influence is included in the simulation. The red point indicates the BHE location (more details in Bayer et al. [21]).

By superposing non-homogeneous solutions for the conductive-dominated problem, Bayer et al. [21] reproduced the measured TDP (Figure 8a). Their procedure was based in a stochastic inversion that yielded estimations of the ground surface temperature of pavements and buildings. Their methodology was also capable of differentiating between the thermal influences due to climate forcing and the identified urban structures. 

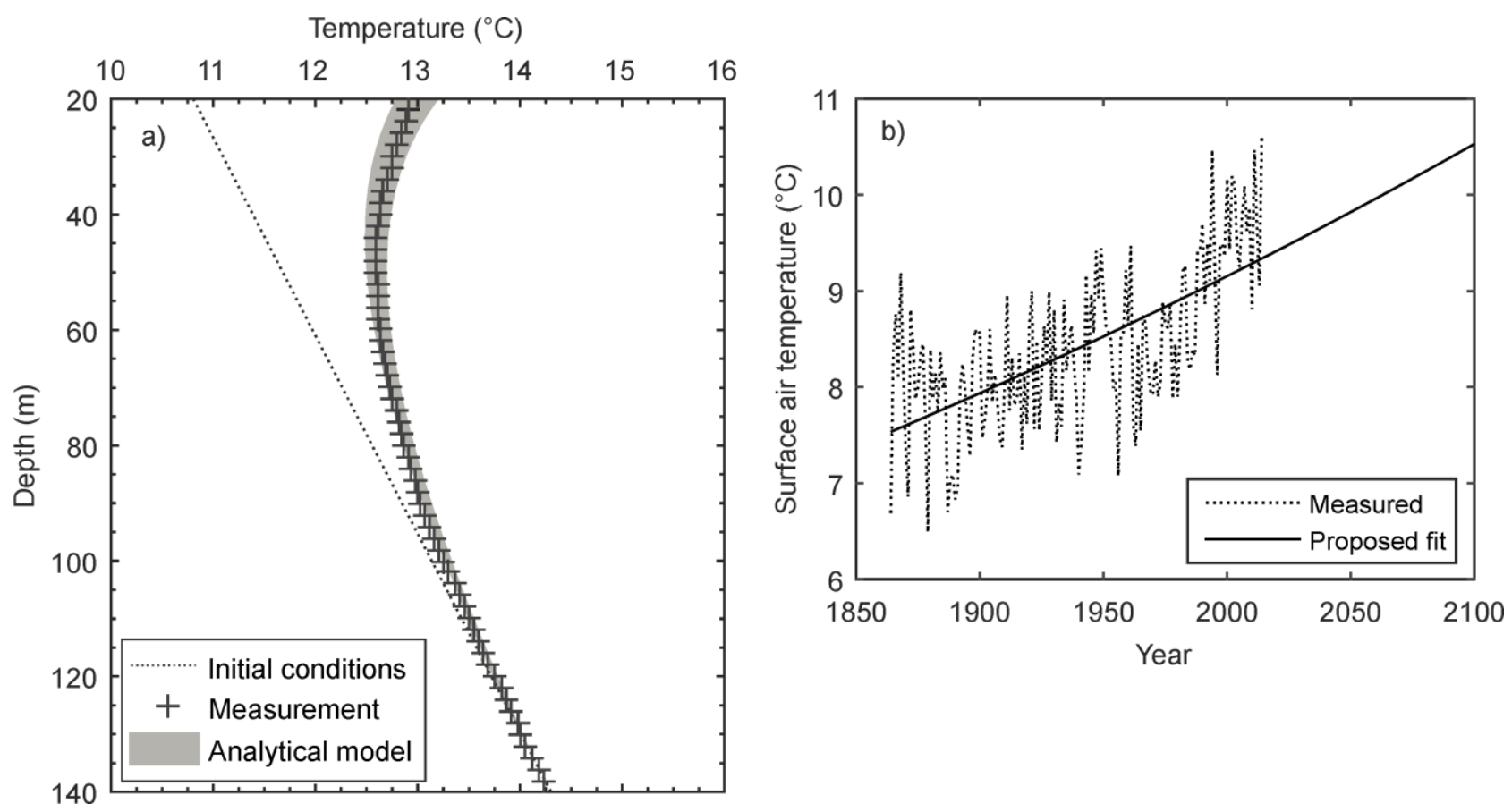

Figure 8: a) Measured and simulated temperature-depth profile (TDP) in the case study (Bayer et al. [21]), and b) surface air temperature (SAT) in the nearby site.

For the estimation of the increased technical potential, this work considers a BHE installed at the measuring point starting operation in 2005 (same year as the measurement). The mean temperature at the borehole wall is obtained by superposing Eq. (4) (for each urban structure) to the background effect representing undisturbed green space. According to Bayer et al. [21], the ground surface temperature for green open spaces and pavements is a function of the surface air temperature (SAT). The latter has been known for the last 130 years with a daily resolution. However, it is necessary to fit an analytical expression in order to extrapolate SAT during the operation time (2005 onwards). The fit curve is shown in Figure $8 \mathrm{~b}$ and follows a logistic model with a maximum of 10.5 ${ }^{\circ} \mathrm{C}$ in 2100 .

For different borehole lengths, Figure 9a depicts the extractable mean annual heat extraction rates under depleting conditions $\left(\overline{T_{\text {fluid }}}=-1.5^{\circ} \mathrm{C}\right.$ after 50 years). Figure $9 \mathrm{a}$ distinguishes two different cases on its left axis: base case without increased ground surface effects $(\mathrm{N})$ and the total effect including urban structures $(\mathrm{N}+\mathrm{U})$. On the right axis of Figure $9 \mathrm{a}$, the rate ratio $(\mathrm{N}+\mathrm{U}) / \mathrm{N}$ is indicated. For $H=100 \mathrm{~m}$ for example, the total increased GST effect $(\mathrm{N}+\mathrm{U})$ allows to extract up to $18 \%$ more energy than in the base case $(\mathrm{N})$. 

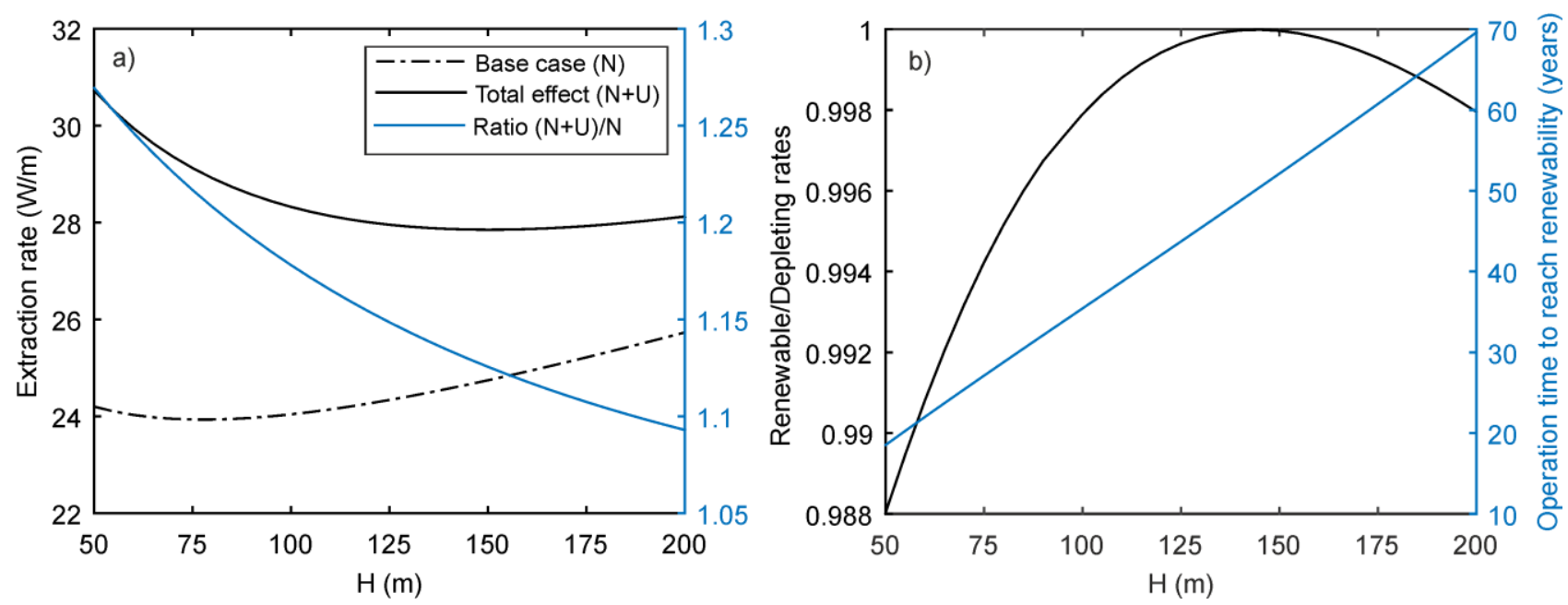

Figure 9: a) Depleting heat extraction rates in the case study for different scenarios: base case $(\mathrm{N})$ and total GST effect $(\mathrm{N}+\mathrm{U})$; b) ratio renewable/depleting rates (left axis) and time to reach short term renewability (right axis).

496 Figure $9 \mathrm{~b}$ shows the ratios between renewable and depleting rates (left axis), as well as the times to reach renewability (right axis). The results indicate that there are not significant differences between 498 the exploitation schemes. This is a consequence of installing a single BHE in an environment with 499 pre-existing warming and agrees with the previous discussion on renewability for single BHEs 500 (Chapter 3.1.3 and Table 2). According to Figure 9b, with a BHE of around $145 \mathrm{~m}$ length, given the 501 SIA requirements, renewable operation after 50 years is feasible. 


\section{Summary and conclusions}

504 This study addresses two major aspects when operating borehole heat exchangers (BHEs) in urban 505 environments. First, it is revealed that the technical geothermal potential of utilizing urban ground 506 can be substantially higher (up to $40 \%$ ) than in rural, open green spaces. This is due to urban ground warming, caused by heat loss and accelerated heat flux from urban structures, which are characteristic for many cities worldwide. Second, it is demonstrated how urban ground warming enhances the renewal of BHEs operated in unbalanced way. For this, ground energy exploitation, within a given time to a given temperature threshold, is compared to long-term renewable operation.

511 A summary of the increased technical potential when comparing feasible heat extraction rates in 512 cities to those in the rural surrounding is provided in Table 3. These values are obtained by taking 513 the ratio of heat extraction rates under different degrees of urbanization divided by the 514 corresponding ones of the non-perturbed base case as listed in Table 2. The increased technical 515 potential is clearly dominated by the relative ground heating, $\Delta T_{G S T}$, while borehole length $H$ and 516 separation $B$ have a secondary role. As expected, the increased potentials are higher for shallower 517 systems. For highly urbanized conditions $\left(\Delta T_{G S T}=5 \mathrm{~K}\right)$, full exploitation rates increase by $13-33$ $518 \%$, and renewable rates by even $19-40 \%$. However, note that the absolute renewable rates are 519 generally lower (Table 2). In essence, this means that either higher energy extraction is feasible in 520 urban ground, or the borehole length can be reduced. As a rough estimate, each additional degree of 521 ground heating saves 4 borehole meters.

Table 3: Increased technical geothermal potential for single $(B=\infty)$ and the representative BHE in an infinite field for different degrees of urbanization and exploitation schemes and $t_{u r b}=100$ years. R: renewable scenario, D: depleting scenario.

\begin{tabular}{|c|c|c|c|c|c|c|c|}
\hline \multirow[b]{3}{*}{$\mathbf{H}(\mathrm{m})$} & \multirow[b]{3}{*}{$\mathbf{B}(\mathbf{m})$} & \multirow{2}{*}{\multicolumn{2}{|c|}{$\begin{array}{c}\text { Low development } \\
\Delta T_{G S T}=\mathbf{1} \mathbf{K}\end{array}$}} & \multirow{2}{*}{\multicolumn{2}{|c|}{$\begin{array}{c}\text { Suburban } \\
\Delta T_{G S T}=\mathbf{3} \mathbf{~ K} \\
\end{array}$}} & \multirow{2}{*}{\multicolumn{2}{|c|}{$\begin{array}{c}\text { Urban } \\
\Delta T_{G S T}=\mathbf{5} \mathbf{K} \\
\end{array}$}} \\
\hline & & & & & & & \\
\hline & & $\mathbf{R}$ & D & $\mathbf{R}$ & D & $\mathbf{R}$ & D \\
\hline \multirow{4}{*}{50} & 10 & 1.08 & \multirow{4}{*}{1.07} & 1.24 & \multirow{4}{*}{1.20} & 1.40 & \multirow{4}{*}{$1.3 ?$} \\
\hline & 20 & 1.08 & & 1.24 & & 1.40 & \\
\hline & 30 & 1.08 & & 1.24 & & 1.40 & \\
\hline & $\infty$ & 1.07 & & 1.20 & & 1.33 & \\
\hline \multirow{4}{*}{100} & 10 & 1.08 & \multirow{4}{*}{1.05} & 1.22 & \multirow{4}{*}{1.14} & 1.37 & \multirow{4}{*}{1.24} \\
\hline & 20 & 1.08 & & 1.22 & & 1.37 & \\
\hline & 30 & 1.08 & & 1.22 & & 1.37 & \\
\hline & $\infty$ & 1.06 & & 1.17 & & 1.27 & \\
\hline \multirow{4}{*}{200} & 10 & 1.07 & \multirow{4}{*}{1.03} & 1.20 & \multirow{4}{*}{1.08} & 1.30 & \multirow{4}{*}{1.13} \\
\hline & 20 & 1.07 & & 1.20 & & 1.32 & \\
\hline & 30 & 1.07 & & 1.20 & & 1.33 & \\
\hline & $\infty$ & 1.05 & & 1.13 & & 1.19 & \\
\hline
\end{tabular}


Table 4 summarizes, what share of the urban heating energy demand (according to [7]) can be covered by operating BHEs in an infinite field. In (sub)urban areas, $4-16 \%$ of the heating demand could be supplied in a renewable way. Apparently, towards the city center the energy demand grows more than the stored geothermal energy. Since replenishment comes mainly from the ground surface, here shallower systems are favorable. However, when full reservoir exploitation is considered, values of up to $40 \%$ can be achieved by deep boreholes of up to $200 \mathrm{~m}$. Not only the accessed ground volume but also the ground heat flux may be decisive for the appropriate borehole depth and configuration. As another example, consider depleting exploitation of warmed urban ground $\left(\Delta T_{G S T}=5 \mathrm{~K}\right)$. Here, the extractable energy is similar for $H=50 \mathrm{~m}$ and $100 \mathrm{~m}$, as reflected by the similar shares of around $20 \%$ listed in Table $4(B=10 \mathrm{~m})$. This is a consequence of the competing effect between accelerated ground heat flux and the geothermal gradient. Considering the highest magnitudes of $\Delta T_{G S T}$ with $\mathrm{t}_{\mathrm{urb}}=100$ years, installing a BHE field with $H=100 \mathrm{~m}$ is not likely the best strategy, since almost the same power can be extracted with a shallower system that takes advantage of the cumulated urban heat. However, for longer BHE fields $(H=200 \mathrm{~m})$ the geothermal gradient dominates and the energy yield is enhanced.

Table 4: Share of the heating demand supplied by an infinite BHE field for different degrees of urbanization and exploitation schemes and $t_{u r b}=100$ years. The considered heating demands (in $\mathrm{kWh} \mathrm{m}^{-2} \mathrm{a}^{-1}$ ) are as follows [7]: 60 for low development areas, 130 for suburban areas and 170 for city centers. R: renewable scenario, D: depleting scenario.

\begin{tabular}{|c|c|c|c|c|c|c|c|}
\hline \multirow[b]{3}{*}{ H (m) } & \multirow[b]{3}{*}{ B (m) } & \multirow{2}{*}{\multicolumn{2}{|c|}{$\begin{array}{c}\text { Low development } \\
\Delta T_{G S T}=1 \mathbf{K} \\
\end{array}$}} & \multirow{2}{*}{\multicolumn{2}{|c|}{$\begin{array}{c}\text { Suburban } \\
\Delta T_{G S T}=\mathbf{3} \mathbf{K} \\
\end{array}$}} & \multirow{2}{*}{\multicolumn{2}{|c|}{$\begin{array}{l}\text { City center } \\
\Delta T_{G S T}=\mathbf{5} \mathbf{K} \\
\end{array}$}} \\
\hline & & & & & & & \\
\hline & & $\mathbf{R}$ & D & $\mathbf{R}$ & D & $\mathbf{R}$ & D \\
\hline \multirow{3}{*}{50} & 10 & $32 \%$ & $47 \%$ & $16 \%$ & $23 \%$ & $14 \%$ & $20 \%$ \\
\hline & 20 & $22 \%$ & $30 \%$ & $11 \%$ & $15 \%$ & $10 \%$ & $12 \%$ \\
\hline & 30 & $15 \%$ & $18 \%$ & $7 \%$ & $9 \%$ & $6 \%$ & $8 \%$ \\
\hline \multirow{3}{*}{100} & 10 & $22 \%$ & $53 \%$ & $11 \%$ & $26 \%$ & $10 \%$ & $21 \%$ \\
\hline & 20 & $17 \%$ & $40 \%$ & $8 \%$ & $19 \%$ & $7 \%$ & $16 \%$ \\
\hline & 30 & $14 \%$ & $28 \%$ & $7 \%$ & $14 \%$ & $6 \%$ & $11 \%$ \\
\hline \multirow{3}{*}{200} & 10 & $18 \%$ & $86 \%$ & $9 \%$ & $40 \%$ & $8 \%$ & $32 \%$ \\
\hline & 20 & $12 \%$ & $69 \%$ & $6 \%$ & $32 \%$ & $5 \%$ & $26 \%$ \\
\hline & 30 & $10 \%$ & $52 \%$ & $5 \%$ & $24 \%$ & $4 \%$ & $19 \%$ \\
\hline
\end{tabular}

545 The findings presented here are crucial for planning geothermal systems in regions with elevated ground temperatures. Such subsurface urban heat islands, however are not only caused by heat loss from basements and accelerated heat flux through paved ground. In cities, there exist several additional sources such as sewage channels, district heating systems or tunnels. Aside from this, long-term atmospheric warming has to be accounted for. All these factors countervail ground 
550 cooling from geothermal energy use, and thus facilitate renewable operation without active 551 replenishment. Strictly speaking, however, we do not tap a naturally renewable energy source. In a 552 nutshell, shallow geothermal systems recycle urban ground heat losses.

553

554 Acknowledgements

555 This work was supported by the Swiss National Science Foundation (SNSF) under grant number 556 200021L 144288, and the German Research Foundation (DFG), under grant number BL 1015/4-1. 557 We thank Rachael Colldeweih for language corrections.

558

559 
561 1. Lund, J.W. and T.L. Boyd, Direct utilization of geothermal energy 2015 worldwide review. $562 \quad$ Geothermics, 2016. 60: p. 66-93.

$5632 . \quad$ Bauer, S., et al., Impacts of the use of the geological subsurface for energy storage: an investigation concept. Environmental earth sciences, 2013. 70(8): p. 3935-3943.

3. Hähnlein, S., et al., Sustainability and policy for the thermal use of shallow geothermal energy. Energy Policy, 2013. 59: p. 914-925.

4. Alcaraz, M., et al., Use rights markets for shallow geothermal energy management. Applied Energy, 2016. 172: p. 34-46.

5. Wagner, R. and T. Weisskopf, Erdsondenpotenzial in der Stadt Zürich. Im Auftrag des Amtes für Hochbauten der Stadt Zürich, 2014.

6. Gemelli, A., A. Mancini, and S. Longhi, GIS-based energy-economic model of low temperature geothermal resources: A case study in the Italian Marche region. Renewable Energy, 2011. 36(9): p. 2474-2483.

7. Schiel, K., et al., GIS-based modelling of shallow geothermal energy potential for CO 2 emission mitigation in urban areas. Renewable Energy, 2016. 86: p. 1023-1036.

8. Ondreka, J., et al., GIS-supported mapping of shallow geothermal potential of representative areas in south-western Germany — possibilities and limitations. Renewable Energy, 2007. 32(13): p. 21862200.

9. Zhang, Y., K. Soga, and R. Choudhary, Shallow geothermal energy application with GSHPs at city scale: study on the City of Westminster. Géotechnique Letters, 2014. 4(April-June): p. 125-131.

10. Casasso, A. and R. Sethi, Territorial Analysis for the Implementation of Geothermal Heat Pumps in the Province of Cuneo (NW Italy). Energy Procedia, 2015. 78: p. 1159-1164.

11. Jaudin, F., et al. ThermoMap-An Open-Source Web Mapping Application for Illustrating the very Shallow Geothermal Potential in Europe and selected Case Study Areas. in European Geothermal Congress 2013, EGC 2013. 2013.

12. Alcaraz, M., et al., Advection and dispersion heat transport mechanisms in the quantification of shallow geothermal resources and associated environmental impacts. Science of The Total Environment, 2016. 543, Part A: p. 536-546.

13. VDI, Thermische Nutzung des Untergrundes (Guideline for thermal use of the underground), in VDI-Richtlinie 4640. 2012, Verein Deutscher Ingenieure (VDI)-Gesellschaft Energietechnik: Germany.

14. Zhang, Y., R. Choudhary, and K. Soga, Influence of GSHP system design parameters on the geothermal application capacity and electricity consumption at city-scale for Westminster, London. Energy and Buildings, 2015. 106: p. 3-12.

15. Arthur, S., et al., Modelling large ground source cooling systems in the Chalk aquifer of central London. Quarterly Journal of Engineering Geology and Hydrogeology, 2010. 43(3): p. 289-306.

16. Menberg, K., et al., Long-Term Evolution of Anthropogenic Heat Fluxes into a Subsurface Urban Heat Island. Environmental science \& technology, 2013. 47(17): p. 9747-9755.

17. Taniguchi, M., T. Uemura, and K. Jago-on, Combined effects of urbanization and global warming on subsurface temperature in four Asian cities. Vadose Zone Journal, 2007. 6(3): p. 591-596.

18. Revesz, A., et al., Ground source heat pumps and their interactions with underground railway tunnels in an urban environment: A review. Applied Thermal Engineering, 2016. 93: p. 147-154.

19. Bidarmaghz, A., et al., The importance of surface air temperature fluctuations on long-term performance of vertical ground heat exchangers. Geomechanics for Energy and the Environment.

20. Eggleston, J. and K.J. McCoy, Assessing the magnitude and timing of anthropogenic warming of a shallow aquifer: example from Virginia Beach, USA. Hydrogeology Journal, 2014: p. 1-16.

21. Bayer, P., et al., Extracting past atmospheric warming and urban heating effects from borehole temperature profiles. Geothermics, under review.

22. Benz, S., et al., Spatial resolution of anthropogenic heat fluxes into urban aquifers. Science of The Total Environment, 2015. 524-525(0): p. 427-439.

23. Müller, N., W. Kuttler, and A.-B. Barlag, Analysis of the subsurface urban heat island in Oberhausen, Germany. Climate research, 2014. 58(3): p. 247-256.

24. Luo, Z. and C. Asproudi, Subsurface urban heat island and its effects on horizontal ground-source heat pump potential under climate change. Applied Thermal Engineering, 2015. 90: p. 530-537. 
25. Zhu, K., et al., The geothermal potential of urban heat islands. Environmental Research Letters, 2010. 5(4): p. 044002.

26. Rybach, L., Classification of geothermal resources by potential. Geothermal Energy Science, 2015. 3: p. 13-17.

27. Yavuzturk, C., Modeling of vertical ground loop heat exchangers for ground source heat pump systems. 1999, Oklahoma State University.

28. Hein, P., et al., A numerical study on the sustainability and efficiency of borehole heat exchanger coupled ground source heat pump systems. Applied Thermal Engineering, 2016. 100: p. 421-433.

29. Aranzabal, N., et al., Extraction of thermal characteristics of surrounding geological layers of a geothermal heat exchanger by 3D numerical simulations. Applied Thermal Engineering, 2016.

30. Perego, R., et al., Sustainability evaluation of a medium scale GSHP system in a layered alluvial setting using 3D modeling suite. Geothermics, 2016. 59, Part A: p. 14-26.

31. Eskilson, P., Thermal analysis of heat extraction boreholes. Ph.D. Thesis, University of Lund, Lund, Sweden, 1987.

32. Li, M. and A.C.K. Lai, Review of analytical models for heat transfer by vertical ground heat exchangers (GHEs): A perspective of time and space scales. Applied Energy, 2015. 151(0): p. 178191.

33. Claesson, J. and S. Javed, An analytical method to calculate borehole fluid temperatures for timescales from minutes to decades. ASHRAE Transactions., 2011. 117(2): p. 279-288.

34. Wei, J., et al., A new analytical model for short-time response of vertical ground heat exchangers using equivalent diameter method. Energy and Buildings, 2016. 119: p. 13-19.

35. Lazzarotto, A., A network-based methodology for the simulation of borehole heat storage systems. Renewable energy, 2014. 62: p. 265-275.

36. Cimmino, M., M. Bernier, and F. Adams, A contribution towards the determination of $g$-functions using the finite line source. Applied Thermal Engineering, 2013. 51(1): p. 401-412.

37. Lamarche, L. and B. Beauchamp, A new contribution to the finite line-source model for geothermal boreholes. Energy and Buildings, 2007. 39(2): p. 188-198.

38. Bandos, T., et al., Finite line-source model for borehole heat exchangers: effect of vertical temperature variations. Geothermics, 2009. 38(2): p. 263-270.

39. Zeng, H., N. Diao, and Z. Fang, A finite line-source model for boreholes in geothermal heat exchangers. Heat Transfer-Asian Research, 2002. 31(7): p. 558-567.

40. Lazzarotto, A., A methodology for the calculation of response functions for geothermal fields with arbitrarily oriented boreholes: Part 1. 2015.

41. Erol, S., M.A. Hashemi, and B. François, Analytical solution of discontinuous heat extraction for sustainability and recovery aspects of borehole heat exchangers. International Journal of Thermal Sciences, 2015. 88: p. 47-58.

42. Cimmino, M. and M. Bernier, A semi-analytical method to generate g-functions for geothermal bore fields. International Journal of Heat and Mass Transfer, 2014. 70: p. 641-650.

43. Lazzarotto, A. and F. Björk, A methodology for the calculation of response functions for geothermal fields with arbitrarily oriented boreholes-Part 2. Renewable Energy, 2016. 86: p. 1353-1361.

44. Rivera, J.A., P. Blum, and P. Bayer, Analytical simulation of groundwater flow and land surface effects on thermal plumes of borehole heat exchangers. Applied Energy, 2015. 146(0): p. 421-433.

45. Rivera, J.A., P. Blum, and P. Bayer, Influence of spatially variable ground heat flux on geothermal systems: Line source model with nonhomogeneous Cauchy-type top boundary conditions. Applied Energy, 2016. Accepted.

46. Carslaw, H. and J. Jaeger, Conduction of Heat in Solids. second ed. 1959, New York: Oxford University Press.

47. Özış1k, M.N., Boundary value problems of heat conduction. 1989: Courier Corporation.

48. Duan, X. and G.F. Naterer, Ground Heat Transfer From a Varying Line Source With Seasonal Temperature Fluctuations. Journal of Heat Transfer, 2008. 130(11): p. 111302-111302.

49. Claesson, J. and P. Eskilson, Conductive heat extraction to a deep borehole: Thermal analyses and dimensioning rules. Energy, 1988. 13(6): p. 509-527.

50. Bayer, P., et al., Extracting past atmospheric warming and urban heating effects from borehole temperature profiles. Geothermics, 2016. 64: p. 289-299.

51. Rivera, J.A., P. Blum, and P. Bayer, Influence of spatially variable ground heat flux on closed-loop geothermal systems: Line source model with nonhomogeneous Cauchy-type top boundary conditions. Applied Energy, 2016. 180: p. 572-585. 
52. Taylor, C.A. and H.G. Stefan, Shallow groundwater temperature response to climate change and urbanization. Journal of Hydrology, 2009. 375(3): p. 601-612.

53. Choi, J.C., J. Park, and S.-R. Lee, Numerical evaluation of the effects of groundwater flow on borehole heat exchanger arrays. Renewable Energy, 2013. 52: p. 230-240.

54. Angelotti, A., et al., Energy performance and thermal impact of a Borehole Heat Exchanger in a sandy aquifer: Influence of the groundwater velocity. Energy Conversion and Management, 2014. 77: p. 700-708.

55. Hagentoft, C.-E., Heat losses and temperature in the ground under a building with and without ground water flow-II. Finite ground water flow rate. Building and Environment, 1996. 31(1): p. 1319.

56. Molina-Giraldo, N., et al., A moving finite line source model to simulate borehole heat exchangers with groundwater advection. International Journal of Thermal Sciences, 2011. 50(12): p. 2506-2513.

57. Rivera, J.A., P. Blum, and P. Bayer, Ground energy balance for borehole heat exchangers: Vertical fluxes, groundwater and storage. Renewable Energy, 2015. 83(0): p. 1341-1351.

58. García-Gil, A., et al., GIS-supported mapping of low-temperature geothermal potential taking groundwater flow into account. Renewable Energy, 2015. 77: p. 268-278.

59. Epting, J., F. Händel, and P. Huggenberger, Thermal management of an unconsolidated shallow urban groundwater body. Hydrology and Earth System Sciences, 2013. 17(5): p. 1851-1869.

60. García-Gil, A., et al., The thermal consequences of river-level variations in an urban groundwater body highly affected by groundwater heat pumps. Science of The Total Environment, 2014. 485486(0): p. 575-587.

61. Zhu, K., et al., Groundwater temperature evolution in the subsurface urban heat island of Cologne, Germany. Hydrological Processes, 2014.

62. Attard, G., et al., Deterministic modeling of the impact of underground structures on urban groundwater temperature. Science of The Total Environment, 2016.

63. Haehnlein, S., P. Bayer, and P. Blum, International legal status of the use of shallow geothermal energy. Renewable and Sustainable Energy Reviews, 2010. 14(9): p. 2611-2625.

64. SIA:384/6, Erdwärmesonden. 2010, Schweizerischer Ingenieur- und Architektenverein: Zürich.

65. Ungemach, P., M. Papachristou, and M. Antics. Renewability versus sustainability. A reservoir management approach. in Proceedings of the European Geothermal Congress. 2007.

66. Stauffer, F., et al., Thermal use of shallow groundwater. 2013: CRC Press.

67. Holmberg, H., et al. Deep Borehole Heat Exchangers, Application to Ground Source Heat Pump Systems. in Submitted to the World Geothermal Congress. 2015.

68. Rybach, L. and W. Eugster, Sustainability aspects of geothermal heat pump operation, with experience from Switzerland. Geothermics, 2010. 39(4): p. 365-369.

69. Kavanaugh, S.P. and K.D. Rafferty, Ground-source heat pumps: design of geothermal systems for commercial and institutional buildings. 1997: American Society of Heating, Refrigerating and AirConditioning Engineers.

70. Menberg, K., et al., Subsurface urban heat islands in German cities. Science of the Total Environment, 2013. 442: p. 123-133.

71. Allegrini, J., et al., A review of modelling approaches and tools for the simulation of district-scale energy systems. Renewable and Sustainable Energy Reviews, 2015. 52: p. 1391-1404.

72. Eskilson, P. and J. Claesson, Simulation model for thermally interacting heat extraction boreholes. Numerical Heat Transfer, 1988. 13(2): p. 149-165.

73. Bayer, P., M. de Paly, and M. Beck, Strategic optimization of borehole heat exchanger field for seasonal geothermal heating and cooling. Applied Energy, 2014. 136: p. 445-453.

74. ARG, Orthofoto SWISSIMAGE 2002 Perimeter des Kantons Zürich. 2002, Amt für Raumentwicklung Geoinformation: Zürich. 